\title{
Model for Metal Extraction from Chloride Media with Basic Extractants: A Coordination Chemistry Approach
}

\author{
Rayco Lommelen, ${ }^{\dagger}$ Tom Vander Hoogerstraete, ${ }^{\dagger}$ Bieke Onghena, ${ }^{\dagger}$ Is Isabelle Billard, ${ }^{\dagger}$ \\ and Koen Binnemans*,†॰
}

\begin{abstract}
${ }^{\dagger}$ KU Leuven, Department of Chemistry, Celestijnenlaan 200F, P.O. Box 2404, B-3001 Leuven, Belgium
${ }^{*}$ Univ. Grenoble Alpes, Univ. Savoie Mont Blanc, CNRS, Grenoble INP (Institute of Engineering Univ. Grenoble Alpes), LEPMI, 38000 Grenoble, France
\end{abstract}

\section{Supporting Information}

ABSTRACT: The metal extraction mechanism of basic extractants is typically described as an anion exchange process, but this mechanism does not correctly explain all observations. This paper introduces a novel model for the extraction of metals by basic extractants from chloride media supported by experimental data on methyltrioctylammonium chloride and Aliquat 336 chloride systems. This model relies on the hypothesis that the metal species least stabilized in the aqueous phase by hydration (i.e., the metal species with the lowest charge density) is extracted more efficiently than the more water stabilized species (i.e., species with higher charge densities). Once it is transferred to the organic phase, the
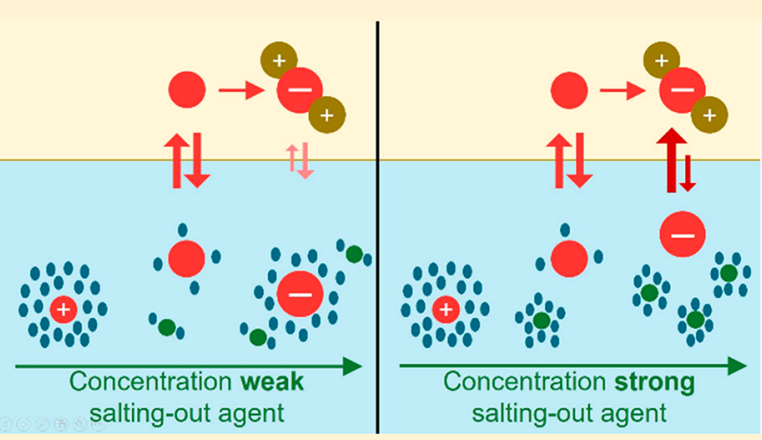
extracted species can undergo further Lewis acid-base adduct formation reactions with the chloride anions available in the organic phase to form negatively charged chloro complexes, which than associate with the organic cations. Salting-out agents influence the extraction, most likely by decreasing the concentration of free water molecules, which destabilizes the metal complex in the aqueous phase. The evidence provided includes (1) the link between extraction and transition-metal speciation, (2) the trend in extraction efficiency as a function of the concentration of different salting-out agents, and (3) the behavior of $\mathrm{HCl}$ in the extraction system. The proposed extraction model better explains the experimental observations in comparison to the anion exchange model and allows the prediction of optimal conditions for metal extractions and separations a priori, by selecting the most suitable salting-out agent and its concentration.

\section{INTRODUCTION}

Solvent extraction is a technique often used for metal separation on an industrial scale, because it can process large volumes in a controllable manner. ${ }^{1,2}$ In conventional solvent extraction, a metal-containing aqueous phase is contacted with an immiscible organic phase (solvent) containing an extractant, a diluent, and sometimes a modifier. The extractant is an organic ligand designed to selectively coordinate to the target metal ions. The diluent is used to increase the solubility of the metal complex in the organic phase and to reduce the viscosity but is in some cases omitted. The modifier is used to change some important physical properties of the organic phase: for instance, to prevent crud formation and to avoid third-phase formation. ${ }^{3}$ During the extraction, metal separation is achieved on the basis of the difference in affinity of the metal ions for the selected extractant. The extractants can be divided into three main classes: (1) cation exchangers or acidic extractants (e.g., alkyl phosphorus acids or carboxylic acids), ${ }^{4,5}$ (2) solvating extractants or neutral extractants (e.g., ketones or organophosphorus esters), ${ }^{2,6}$ and (3) anion exchangers or basic extractants (e.g., protonated amines or quaternary ammonium salts). ${ }^{7-10}$
The extraction mechanism of metals by basic extractants is typically described as an anion exchange process in which a negatively charged metal complex present in the aqueous phase is exchanged for anions in the organic phase (eq 1).

$$
\left[\mathrm{MX}_{y}\right]^{n-}+n \overline{[\mathrm{Q}][\mathrm{X}]} \rightleftharpoons \overline{\left[\mathrm{Q}_{n}\left[\mathrm{MX}_{y}\right]\right.}+n \mathrm{X}^{-}
$$

In eq $1, \mathrm{M}$ represents the metal, $\mathrm{X}$ is a metal-coordinating anion (e.g., $\left.\mathrm{Cl}^{-}, \mathrm{NO}_{3}{ }^{-}, \mathrm{SCN}^{-}, \ldots\right), \mathrm{Q}$ is a cation (e.g., protonated amine, quaternary ammonium ion, ...) and the horizontal bars indicate species in the organic phase.

The extraction of metals by basic extractants is assumed to be facilitated by the formation of the anionic $\left[\mathrm{MX}_{y}\right]^{n-}$ complex in the aqueous phase (eq 2). ${ }^{1,112}$ A sufficiently high concentration of the metal-coordinating anion $\mathrm{X}^{-}$added as a salt or acid is thus required (Figure 1).

$$
\mathrm{M}^{z+}+y \mathrm{X}^{-} \rightleftharpoons\left[\mathrm{MX}_{y}\right]^{n-} \quad \text { with } n=z \text { and } y>z
$$

Also, the type of salt or acid determines the extraction efficiency of a metal to a certain extractant. For instance, the

Received: June 15, 2019

Published: August 27, 2019 


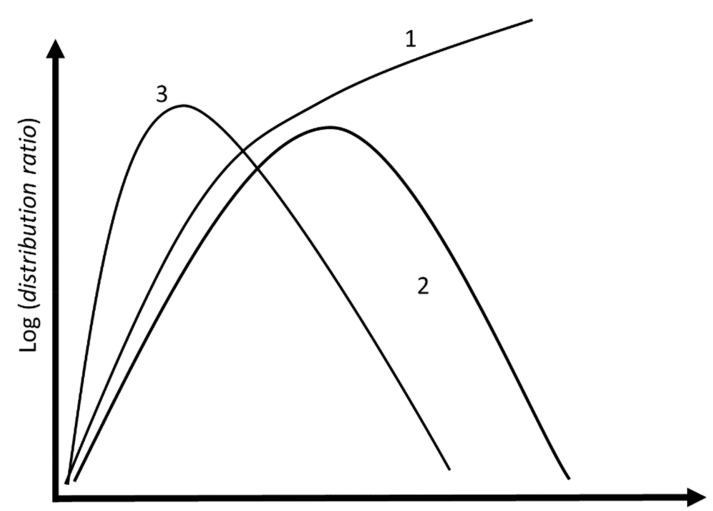

Salting-out concentration

Figure 1. Typical shapes of curves showing the distribution ratios of a metal ion as a function of the salting-out concentration with (1) $\mathrm{LiCl}$ as salting-out agent, (2) $\mathrm{HCl}$ as salting-out agent, or (3) $\mathrm{HCl}$ as salting-out agent in cases where the metal forms strong chloride complexes. It is assumed that there is only one species in the organic phase.

distribution ratio for extraction of metal ions from an aqueous solution containing $8 \mathrm{~mol} \mathrm{~L}^{-1} \mathrm{LiCl}$ is higher than that from 8 mol L ${ }^{-1} \mathrm{HCl}$ (Figure 1, curves 1 and 2). The extraction of metal ions from $\mathrm{HCl}$ media typically shows a maximum in the graph of the distribution ratio as a function of the $\mathrm{HCl}$ concentration at intermediate $\mathrm{HCl}$ concentrations, resulting in a "bell-shaped" curve (Figure 1, curve 2). This phenomenon has been attributed to the presence of the $\mathrm{HCl}_{2}^{-}$species, which competes with the anionic metal complex for the extractant. ${ }^{13}$ The specific anion-metal interactions also have an influence on the extractability of a certain metal. For instance, metal ions forming strong chloro complexes have a maximum in their distribution ratios at a lower $\mathrm{HCl}$ concentration compared to metal ions that form weaker chloro complexes (Figure 1, curve 3).

Historically, the term anion exchange originates from salt metathesis reactions, in which the anion initially present in the organic phase is exchanged by another anion initially present in the aqueous phase. For instance, anion exchange resins, which are solid supports that trap ions from a solution, are based on this phenomenon. ${ }^{14}$ The exchange between anions can be predicted by the Hofmeister series for anions (eq 3). ${ }^{15-17}$ Hydrophilic ions, in general anions with a high charge density, will preferentially distribute to the aqueous phase (left side of the series), whereas hydrophobic anions, which generally have a low charge density, will preferentially distribute to the organic phase (right side of the series).

$$
\begin{aligned}
& \text { citrate }^{3-}<\mathrm{SO}_{4}^{2-}<\mathrm{HPO}_{4}^{2-}<\mathrm{F}^{-}<\mathrm{Cl}^{-}<\mathrm{Br}^{-}<\mathrm{I}^{-} \\
& <\mathrm{NO}_{3}^{-}<\mathrm{ClO}_{4}^{-}<\mathrm{SCN}^{-}
\end{aligned}
$$

Although many examples of the extraction of metals by basic extractants have been reported in the literature, the extraction mechanism has not been fully elucidated yet due to difficulties in describing all of the equilibria involved in the extraction process. ${ }^{1}$

Several interactions occur between the basic extractant in the organic phase and the metal-coordinating anion $\mathrm{X}^{-}$in the aqueous phase. First, Brønsted basic amines that can be used as basic extractants extract acids via an acid-base reaction to yield an ammonium salt of the form $[\mathrm{AH}][\mathrm{X}]$, with A being an amine. Second, basic extractants might form oligomers in the nonpolar organic phase. ${ }^{18}$ Third, the basic extractant is involved in the extraction of the metal, and fourth, all of these equilibria depend on the nature of the diluent. Moreover, the driving force behind extraction is the addition of salt to the aqueous phase. This salt addition not only changes the metal speciation in the aqueous phase but also changes the ionic strength and thus the activity of the species in the aqueous phase. Hence, it is very difficult to determine stability constants and derive appropriate equations for the extraction of metals by basic extractants. Moreover, additional equilibria occur at high salt concentrations related to the association of the salting-out cation with the anion, reducing the "free" anion concentration in the aqueous phase (e.g., the formation of $\mathrm{CaCl}^{+}$by coordination of $\mathrm{Cl}^{-}$to $\mathrm{Ca}^{2+}$ ). Finally, various anionic metal species are present in the organic phase as well.

The difficulty in explaining all observations made from metal extractions with basic extractants has attracted attention in the recent literature. Uchikoshi et al. investigated the aqueous coordination chemistry of $\mathrm{Cu}$ (II) and $\mathrm{Co}$ (II) and tried to relate their findings to the adsorption of $\mathrm{Cu}$ (II) and $\mathrm{Co}(\mathrm{II})$ to anion exchange resins. They concluded that an anion exchange mechanism for adsorption on resins was correct, although significant adsorption was already found when only very low concentrations of anionic species were present. ${ }^{19,20}$ Also, no explanation for the decreasing adsorption efficiency at high $\mathrm{HCl}$ concentrations could be given. Onghena et al. ${ }^{21}$ and Vander Hoogerstraete et al. $^{22}$ investigated the speciation of trivalent lanthanide ions in solvent extraction systems and concluded that the speciations in the aqueous and organic phase are different. Deferm et al. studied the solvent extraction and speciation of $\operatorname{In}(\mathrm{III})$ and related the aqueous $\operatorname{In}(\mathrm{III})$ species to the extraction efficiency of In(III) ${ }^{23}$ In addition, the extraction mechanism of $\mathrm{Fe}$ (III) with Cyphos IL 101 has received some attention. ${ }^{24}$ The authors proposed that $\mathrm{Fe}$ (III) can also be extracted as $\mathrm{FeCl}_{3}$ via an ion association mechanism together with the extraction of $\mathrm{FeCl}_{4}^{-}$via an anion exchange mechanism.

In this paper, an alternative model for the extraction of metals by basic extractants from chloride media is presented. This model better explains the experimental observations described in the literature and therefore is probably closer to the true extraction mechanism. Although the term extraction mechanism often refers to how a metal is transferred from the aqueous into the organic phase (the net reaction equation), the current approach rather focuses on how the extraction equilibrium state is reached and how it is influenced by the aqueous and organic phases. After introduction of the new model, it is experimentally tested by studying the influence of salting-out agents on the distribution ratios of $\mathrm{Cu}(\mathrm{II}), \mathrm{Co}(\mathrm{II})$, and $\mathrm{Zn}(\mathrm{II})$ and relating the results to the ionic strength, speciation, and hydration of the metal complexes in the aqueous phase, as well as the speciation in the organic phase. Also, the behavior of $\mathrm{HCl}$ in solvent extractions using basic extractants is considered to investigate the supposed competition between $\mathrm{HCl}$ and metal extraction reported in the literature. ${ }^{13,25-29}$

\section{EXPERIMENTAL SECTION}

2.1. Chemicals. An aqueous solution of hydrogen bis(trifluoromethylsulfonyl)imide (80\%) was purchased from Iolitec (Heilbronn, Germany). $\mathrm{HNO}_{3}$ (65 wt \%), $\mathrm{NH}_{4} \mathrm{Cl}$ (99.99\%), $\mathrm{NaCl}$ (99.99\%), $\mathrm{LiCl}$ (99.9\%), $\mathrm{NaOH}(0.1 \mathrm{M}), \mathrm{HCl}$ ( 37 wt \%), and 
toluene were purchased from VWR (Leuven, Belgium). $\mathrm{CuO}$ (99.99\%), $\mathrm{CuCl}_{2}$ (99.995\%), $\mathrm{MgCl}_{2} \cdot 2 \mathrm{H}_{2} \mathrm{O}$ (>99\%), $\mathrm{CaCl}_{2} \cdot 2 \mathrm{H}_{2} \mathrm{O}$ (>99\%), $\mathrm{AlCl}_{3} \cdot 6 \mathrm{H}_{2} \mathrm{O}(>99 \%)$, and Aliquat 336 were purchased from Sigma-Aldrich (Overijse, Belgium). The cesium, copper, cobalt, scandium, indium and zinc aqueous standards $\left(1000 \mathrm{mg} \mathrm{L}^{-1}\right.$ in $3-5 \%$ $\left.\mathrm{HNO}_{3}\right)$, lanthanum organic standard $\left(1000 \mu \mathrm{g} \mathrm{g}^{-1}\right.$ in Standard matrix oil 55-65 mPas), $\mathrm{CoCl}_{2} \cdot 6 \mathrm{H}_{2} \mathrm{O}$ (>98\%), $\mathrm{ZnCl}_{2}$ (>98\%), and $\mathrm{KCl}$ ( $>99.5 \%$ ) were obtained from Chem Lab (Zedelgem, Belgium). Methyltrioctylammonium chloride (98\%) was purchased from J\&K Scientific (Lommel, Belgium). CsCl (>99.9\%) was obtained from Carl Roth (Karlsruhe, Germany). Ethanol (absolute, >99.8\%) was purchased from Fisher Scientific (Merelbeke, Belgium). Water was always of ultrapure quality, deionized to a resistivity of $>18.2 \mathrm{M} \Omega \mathrm{cm}$ at $25^{\circ} \mathrm{C}$ with a Merck MilliPore MilliQ Reference A+ ultrapure water system. All chemicals were used as received, without any further purification.

2.2. Metal Extraction and Quantification. Metal extractions $(\mathrm{Cu}(\mathrm{II}), \mathrm{Co}(\mathrm{II})$, and $\mathrm{Zn}(\mathrm{II}))$ were performed with $1 \mathrm{~mL}$ of an aqueous phase (taken from $10 \mathrm{~mL}$ of an aqueous phase) and $1 \mathrm{~mL}$ of an organic phase in glass vials with a volume of $4 \mathrm{~mL}$. The metal concentration in the aqueous phase was kept constant by adding a fixed volume of an aqueous metal stock solution to an aliquot of a highly concentrated acid or salt solution $(\mathrm{HCl}, \mathrm{LiCl}, \mathrm{NaCl}, \mathrm{KCl}, \mathrm{CsCl}$, $\mathrm{MgCl}_{2}, \mathrm{CaCl}_{2}, \mathrm{AlCl}_{3}$, or $\mathrm{NH}_{4} \mathrm{Cl}$ ), which was subsequently diluted with a certain volume of ultrapure water to a total volume of $10 \mathrm{~mL}$. The final concentrations of $\mathrm{Cu}$ (II), $\mathrm{Co}$ (II), and $\mathrm{Zn}$ (II) in the aqueous samples were $0.5,1.0$, and $2.0 \mathrm{~g} \mathrm{~L}^{-1}$, respectively. A higher concentration of $\mathrm{Zn}$ (II) was chosen, as it is extracted much more efficiently, making it harder to accurately quantify in the aqueous phase after extraction. The salt solutions were prepared by working close to the solubility limit. The exact salt concentrations were calculated on the basis of the densities of the prepared solutions. In this way, weighing errors due to the uptake of water by the hygroscopic salts were avoided. ${ }^{30}$ The concentrations of the salt solutions of $\mathrm{AlCl}_{3}$ were calculated on the basis of the mass of the dissolved solid because of the unavailability of data concerning the density-concentration relationship. A $0.5 \mathrm{~mL}$ portion of $12 \mathrm{~mol} \mathrm{~L}^{-1}$ $\mathrm{HCl}$ was added to $25 \mathrm{~mL}$ of the $\mathrm{AlCl}_{3}$ salt solution to avoid hydrolysis of $\mathrm{Al}(\mathrm{III})$, and $0.0225 \mathrm{~mol} \mathrm{~L}^{-1} \mathrm{HCl}$ was added to all $\mathrm{Zn}$ (II) aqueous phases to avoid hydrolysis of $\mathrm{Zn}$ (II) during extraction.

The organic phase was made by diluting methyltrioctylammonium chloride (TOMAC) (dried overnight on a Schlenk line at room temperature) in toluene to a concentration of $0.2 \mathrm{~mol} \mathrm{~L}^{-1}$. All extractions were performed by shaking at $2000 \mathrm{rpm}$ for $30 \mathrm{~min}$ at room temperature, and phase separation was accomplished by centrifugation for $2 \mathrm{~min}$ at $5000 \mathrm{rpm}$.

The metal concentration in the aqueous phase before and after extraction was measured using ICP-OES, and the aqueous $\mathrm{HCl}$ concentration was corrected for the loss of $\mathrm{HCl}$ to the organic phase, on the basis of $\mathrm{HCl}$ extraction experiments. Distribution ratios $(D)$ were calculated with the formula

$$
D=\frac{c_{\mathrm{M}, \mathrm{org}}}{c_{\mathrm{M}, \mathrm{aq}}}
$$

where $c_{\mathrm{M} \text {,aq }}$ and $c_{\mathrm{M} \text {,org }}$ are the equilibrium metal concentrations in the aqueous and organic phases after extraction, respectively. The concentration of metal in the organic phase was calculated via the mass balance. In the case of equal volumes of organic and aqueous phases, eq 3 can be rewritten as

$$
D=\frac{c_{\mathrm{M}, \mathrm{aq}, 0}-c_{\mathrm{M}, \mathrm{aq}}}{c_{\mathrm{M}, \mathrm{aq}}}
$$

with $c_{\mathrm{M}, \mathrm{aq}, 0}$ being the initial metal concentration in the aqueous phase. The experimental error was calculated on the basis of triplicate measurements and was less than $5 \%$. Error bars on graphs were omitted for the sake of legibility.

2.3. $\mathrm{HCl}$ Extraction and Quantification. Extractions of $\mathrm{HCl}$ were performed with $5.0 \mathrm{~mL}$ of aqueous phase and $5.0 \mathrm{~mL}$ of organic phase in $15 \mathrm{~mL}$ centrifuge tubes. The $\mathrm{HCl}$ concentration was determined via its density. The organic phase was water-saturated Aliquat 336, water-saturated TOMAC, or $0.23 \mathrm{~mol} \mathrm{~L}^{-1}$ Aliquat 336 in toluene $\left(0.2 \mathrm{~mol} \mathrm{~L}^{-1}\right.$ quaternary compound; commercial Aliquat 336 has 90 wt \% quaternary salt compounds and also amine and alcohol impurities). ${ }^{31}$ All organic phases were presaturated with water to avoid large volume changes. Extractions were performed using a Burrel Wrist-Action shaker at room temperature for $1 \mathrm{~h}$ at $450 \mathrm{rpm}$. Afterward the $\mathrm{HCl}$ concentration in the aqueous phase was determined via its density and corrections were made for volume changes, determined visually using a graduated cylinder (deviation $\pm 0.1 \mathrm{~mL}$ ). The organic water content was determined using Karl Fischer titration.

2.4. Instrumentation and Analysis Methods. UV-vis absorption spectra of the aqueous phases were measured with an Agilent Cary 6000i spectrophotometer and Cary WinUV software. Metal ion concentrations were determined by inductively coupled plasma-optical emission spectroscopy (ICP-OES), with a PerkinElmer Avio 500 spectrometer equipped with an axial/radial dual plasma view, a GemCone High Solids nebulizer, a baffled cyclonic spray chamber, and a demountable quartz torch with a $2.0 \mathrm{~mm}$ internal diameter alumina injector. Samples, calibration solutions, and quality control solutions were diluted with $\mathrm{HNO}_{3}$ (2 vol \%). All ICP-OES spectra were measured in triplicate. Calibration curves were made using solutions of $0.1,1$, and $10 \mathrm{mg} \mathrm{L}^{-1}$ of the corresponding metal from a standard solution. Quality checks were performed with $5 \mathrm{mg}$ $\mathrm{L}^{-1}$ metal in different concentrations of the salt, equal to the matrix concentrations after dilution. In(III) or Sc(III) was added and applied as internal standard only if the quality checks failed because of matrix effects.

Densities of the acid and salt solutions were measured with an Anton Paar DMA $4500 \mathrm{M}$ densitometer. A Nemus Life Thermo Shaker TMS-200 was used for the extraction experiments. A Heraeus Labofuge 200 centrifuge was used to accelerate phase separation. The water content in the organic phases was measured using a MettlerToledo V30S volumetric Karl Fischer titrator. For this, the $\mathrm{HCl}$ in the organic phase $(2 \mathrm{~mL})$ was neutralized prior to titration using triethylamine $(10 \mathrm{~mL})$ in dry methanol $(10 \mathrm{~mL})$ to avoid interference in the measurements.

2.5. Synthesis. Copper bis(trifluoromethylsulfonyl)imide $(\mathrm{Cu}-$ $\left.\left(\mathrm{Tf}_{2} \mathrm{~N}\right)_{2}\right)$ was synthesized by mixing $\mathrm{Cu}(\mathrm{II})$ oxide $(\mathrm{CuO})(1.5 \mathrm{~g}, 18.8$ $\mathrm{mmol})$ with hydrogen bis(trifluoromethylsulfonyl)imide $\left(\operatorname{HTf}_{2} \mathrm{~N}\right.$, $5.53 \mathrm{~g}, 15.7 \mathrm{mmol}$ ) in water for $4 \mathrm{~h}$ at $80{ }^{\circ} \mathrm{C}$ in a sealed vial. Afterward, excess $\mathrm{CuO}$ was removed by filtration. The obtained metal solution was measured by ICP-OES and used as a metal stock solution for the UV-vis measurements of the aqueous phase from 0 to $2 \mathrm{~mol} \mathrm{~L}{ }^{-1} \mathrm{HCl}$. A $50 \mathrm{~mL}$ portion of the stock solution was removed, and water was evaporated by a rotary evaporator. Afterwards, the obtained $\mathrm{Cu}\left(\mathrm{Tf}_{2} \mathrm{~N}\right)_{2}$ salt was dissolved in $50 \mathrm{~mL}$ of $\sim 37 \mathrm{wt} \% \mathrm{HCl}\left(12 \mathrm{~mol} \mathrm{~L}^{-1}\right)$ and used as a metal stock solution for the UV-vis measurements of the aqueous phase between 2 and 12 mol L ${ }^{-1} \mathrm{HCl}$.

2.6. Calculations. The UV-vis absorption spectra were analyzed following the multivariate curve resolution-alternative least squares (MCR-ALS) technique using the MCR-ALS GUI 2.0 toolbox working in Matlab R2018b software. ${ }^{32}$ Chemical constraints were fixed to a minimum: (1) the total amount of the metal was normalized, (2) the independent UV-vis absorption spectra do not have negative absorbance values, and (3) the concentrations of the species cannot be negative. Principal component analysis (PCA) (using the same toolbox in Matlab) was performed prior to the MCR-ALS study to determine how many different species were present in the solutions, and the results were compared with the literature.

The results of the MCR-ALS analysis are displayed as the UV-vis absorption spectra of the independent metal species present in all samples containing that metal ion and as the mole fraction of all species in function of the acid or salt concentration. The mole fraction of a metal species $\left(\mathrm{M}^{2+}\right)$ is expressed as

$$
x_{\left[\mathrm{MCl}_{x}\right]^{2-x}}=\frac{n_{\left[\mathrm{MCl}_{x}\right]^{2-x}}}{\sum_{i=0}^{m} n_{\left[\mathrm{MCl}_{i}\right]^{2-i}}}
$$


with $m$ being the maximum amount of chlorides coordinated to $\mathrm{M}^{2+}$ and $n$ being the number of moles of a species.

Note that this mathematical treatment of the data is not based on any chemical model. Therefore, ascribing a UV-vis absorption spectrum to a certain metal complex is done by considering the change in the concentration percentages as a function of the $\mathrm{HCl}$ concentration and/or by comparison with previously published UVvis absorption spectra. ${ }^{33}$

\section{RESULTS AND DISCUSSION}

3.1. New Extraction Model. The term anion exchange has been taken over by practitioners in the field of solvent extraction from the field of ion exchange. However, this term does not completely fit with experimental observations, for several reasons. For instance, lanthanides $(\mathrm{Ln})$ are extracted from nitrate media as $\left[\mathrm{Ln}\left(\mathrm{NO}_{3}\right)_{5}\right]^{2-}$ complexes by basic extractants, but it has been shown that, even at very high nitrate concentrations, only hydrated $\left[\mathrm{Ln}\left(\mathrm{NO}_{3}\right)\right]^{2+}$ species exist in the aqueous phase and no $\left[\mathrm{Ln}\left(\mathrm{NO}_{3}\right)_{5}\right]^{2-}$ species. $^{21,34}$ The situation is even more striking in the case of a split-anion extraction, where lanthanides are extracted from aqueous chloride media to a nitrate organic phase in the form of $\left[\mathrm{Ln}\left(\mathrm{NO}_{3}\right)_{5}\right]^{2-}$ complexes. $^{35}$ Also in chloride media, only positively charged lanthanide complexes exist and efficient extraction to basic extractants is observed at high $\mathrm{LiCl}$ concentrations. $^{22}$ The extraction of $\operatorname{In}(\mathrm{III})$ is a second example for which an anion exchange mechanism does not fit the observations. The anion exchange mechanism cannot explain the change in speciation: $\operatorname{In}(\mathrm{III})$ is present in the aqueous phase as the octahedral $\left[\operatorname{InCl}_{x}\left(\mathrm{H}_{2} \mathrm{O}\right)_{6-x}\right]$ complex $(x \leq 3)$, while it is present in the organic phase as the tetrahedral $\left[\mathrm{InCl}_{4}\right]^{-}$complex. ${ }^{23}$ The experimental data of many reported metal extraction studies from $\mathrm{HCl}$ media do not support the anion exchange hypothesis: a decrease in distribution ratio as a function of the $\mathrm{HCl}$ concentration (Figure 1, curves 2 and 3 ) is not in accordance with Le Châtelier's principle. The combination of eqs 1 and 2 demonstrates that any increase in chloride concentration should shift the equilibrium to the right, thus increasing the extraction. The decrease in distribution ratio has often been attributed to the coextraction of $\mathrm{HCl}$ as the anion species $\mathrm{HCl}_{2}^{-}$into the organic phase, competing with the metal extraction. ${ }^{13,25-29}$ However, no direct evidence for the competition between metal and $\mathrm{HCl}$ extraction can be found in the literature. Furthermore, a decreasing distribution ratio at high chloride concentrations to Aliquat 336 is observed for the extraction of $\mathrm{Zn}$ (II) from $\mathrm{LiCl}$ media and decreasing distribution ratios of $\mathrm{Zn}$ (II) are also discovered for different chloride salt solution-anion exchange resin systems. ${ }^{36,37}$ In this case, no competition between $\mathrm{LiCl}$ and $\mathrm{Zn}$ (II) extraction occurs, as $\mathrm{LiCl}$ is not extracted. Also, the decreasing distribution ratios cannot be explained by a changing speciation in the organic phase or because of a changing composition of the organic phase, as the composition of the organic phase is almost constant over the whole $\mathrm{LiCl}$ range. ${ }^{38}$

The analysis of former extraction studies and the difficulty of explaining the whole extraction process with currently accepted theories show that another model is required to describe the extraction of metals by basic extractants. An alternative extraction model for the extraction of metals from chloride media with basic extractants is proposed here and experimentally tested as described in the next sections. The experiments were all performed in chloride media, resulting only in a direct validation of the proposed model for chloride media. However, the proposed model most likely also explains metal extraction with basic extractants from other media, as no part of the proposed model is exclusively developed for chlorides. The new model is explained for a divalent metal ion $\left(\mathrm{M}^{2+}\right)$ and its four different chloro complexes in the aqueous phase $\left(\left[\mathrm{MCl}_{x}\right]^{2-x}\right.$ with $\left.0 \leq x \leq 4\right)$ but can be applied to metal ions with another charge and a different aqueous speciation, as well (Figure 2).
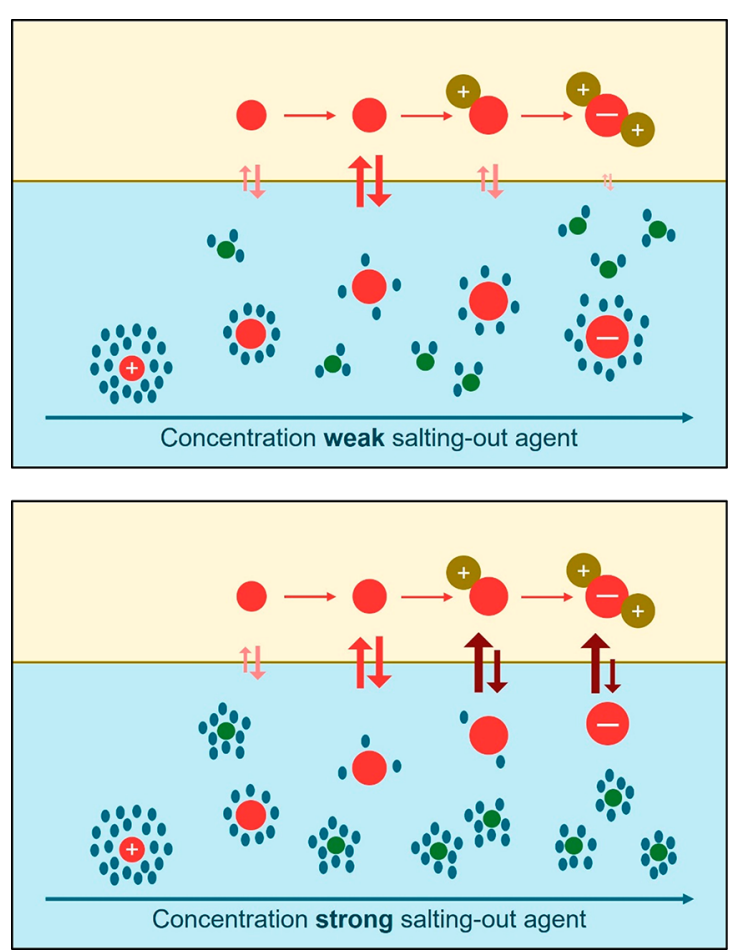

Figure 2. Model for the extraction of a metal ion from weak (top) and strong (bottom) salting-out agents. The metal ion is depicted in red and changes from positively charged at low salting-out agent concentration to negatively charged by the complexation of saltingout anions. The salting-out cations are depicted in green, the associated water molecules are shown in blue, and the organic cations are illustrated in brown-yellow. The size and color of the arrows represent the relative extraction efficiency (increasing size and darkening color represent increasing extraction efficiency).

At low chloride concentrations, $\mathrm{M}^{2+}$ is hydrated in its first, second, and even third coordination spheres by a large number of water molecules (its hydration sphere). When the chloride concentration is increased, there is a shift toward the formation of more $[\mathrm{MCl}]^{+}$and $\mathrm{MCl}_{2}$ complexes. The charge density of the $[\mathrm{MCl}]^{+}$species is lower than that of $\mathrm{M}^{2+}$, decreasing the hydration sphere and hydration enthalpy. The $\mathrm{MCl}_{2}$ complex has no charge, and the total number of hydrating water molecules in its hydration sphere is at a minimum. At higher chloride concentrations, the species $\left[\mathrm{MCl}_{3}\right]^{-}$and $\left[\mathrm{MCl}_{4}\right]^{2-}$ are formed, for which the charge density increases again, resulting in larger hydration spheres and higher hydration energies. Housecraft et al. found that the hydration enthalpy is proportional to the square of the ion charge and the inversed cubic root of the ion volume, showing that the hydration energy indeed increases with increasing charge density. ${ }^{39}$ Dupont et al. have postulated that a species with a lower hydration enthalpy distributes into the organic phase more 
favorably. ${ }^{17}$ As a result, the maximum in the distribution ratio is found close to the $\mathrm{HCl}$ concentration at which the fraction of metal species with the lowest charge density (e.g., $\mathrm{MCl}_{2}$ ) in the aqueous phase is the highest. The smallest distribution ratios will be found at those $\mathrm{HCl}$ concentrations at which the fraction of the metal species with the highest charge densities (e.g., $\mathrm{M}^{2+}$ or $\left[\mathrm{MCl}_{4}\right]^{2-}$ ) is the highest in the aqueous phase. This model is shown in Figure 2.

A contribution to the thermodynamics of the extraction process which is overlooked when the extraction process is considered only from the perspective of the hydration enthalpy of the metal complex is the effect of chloride anions expelled to the aqueous phase or taken up by the organic phase when charged complexes $\left(\left[\mathrm{MCl}_{x}\right]^{2-x}\right.$ with $\left.x \neq 2\right)$ are extracted. This is required to preserve the charge balance of the extraction process. However, this omission is justified for a qualitative description of the extraction process. This can be understood by envisioning the extraction process as a series of elementary thermodynamic steps: (1) the formation of the neutral $\mathrm{MCl}_{2}$ complex, (2) the extraction of the complex to the organic phase, and (3) the formation of a Lewis acid-base adduct between the neutral metal complex and chloride anions in the organic phase. These elementary thermodynamic steps are not necessarily the exact reaction path for the extraction of a charged metal species but can be used to visualize the extraction process, as the final thermodynamic state of a chemical process is independent of the chosen path (known as Hess' law). As an example, the extraction of $\left[\mathrm{MCl}_{3}\right]^{-}$is illustrated by eqs 7-9:

$$
\begin{aligned}
& {\left[\mathrm{MCl}_{3}\right]^{-} \rightleftharpoons\left[\mathrm{MCl}_{2}\right]+\mathrm{Cl}^{-}} \\
& {\left[\mathrm{MCl}_{2}\right] \rightleftharpoons \overline{\left[\mathrm{MCl}_{2}\right]}} \\
& \overline{\left[\mathrm{MCl}_{2}\right]}+\overline{x[\mathrm{Q}][\mathrm{Cl}]} \rightleftharpoons \overline{\left[\mathrm{Q}_{x}\left[\mathrm{MCl}_{2+x}\right]\right.}
\end{aligned}
$$

The last two steps of the process are independent of the initial metal speciation and are always favorable. The first process is always unfavorable, as this requires a change in the speciation of the metal complex to an off-equilibrium state. As a result, the extraction will be the most efficient when the initial concentration of $\mathrm{MCl}_{2}$ is maximum, as this minimizes the need for unfavorable speciation changes. The loss of hydration enthalpy of the charged metal complex is an important contribution to the unfavorable nature of the speciation change of the metal complex.

The chloride concentration and linked metal speciation are not the only influences on the hydration of the metal complex. Also, the availability of water molecules that can hydrate the metal complex, i.e. the water activity, has an influence on the extraction. The availability of water molecules for the metal complex can be changed by the choice of cation of the salt which provides the chlorides in the aqueous phase. A cation with a large charge density, such as $\mathrm{Li}^{+}$, is strongly hydrated, making the water molecules less available for the metal complex $\left(\left[\mathrm{MCl}_{x}\right]^{2-x}\right)$. This decreases the size of the hydration shell and the hydration enthalpy of the $\left[\mathrm{MCl}_{x}\right]^{2-x}$ species in the aqueous phase at high ionic strength, resulting in higher distribution ratios. This is known as the salting-out effect. ${ }^{40}$ This is also visualized in Figure 2. A cation with a lower charge density ( such as $\mathrm{K}^{+}$) will not be hydrated to such an extent, and more water molecules will be available for binding to the metal complex.
This extraction model can give new insights into the extraction of metals by basic extractants, and it gives an explanation for poorly understood extraction phenomena. First, lanthanide ions are extracted by basic extractants as positively charged and hydrated metal complexes $\operatorname{Ln}\left(\mathrm{H}_{2} \mathrm{O}\right)_{x}^{3+}$ at high $\mathrm{LiCl}$ concentration, which cannot be explained by the anion exchange mechanism. ${ }^{22}$ However, the new model states that the hydration (in all coordination spheres) of the metal complexes determines the extraction efficiency. The Ln$\left(\mathrm{H}_{2} \mathrm{O}\right)_{x}{ }^{3+}$ complexes are less hydrated at very high $\mathrm{LiCl}$ concentrations due to the low water activity and thus are extracted more easily. Second, the generally accepted principle that the decrease in metal extraction at higher $\mathrm{HCl}$ concentrations is due to competition between metal and $\mathrm{HCl}$ extraction via the $\mathrm{HCl}_{2}^{-}$species is contradicted by the newly proposed model. The new model attributes the decrease in distribution ratio at high chloride concentrations to the formation of more strongly hydrated metal complexes in the aqueous phase, instead of the competition between $\mathrm{HCl}$ and metal extraction. Third, the fraction of the metal species with the lowest charge density in the aqueous phase (e.g., $\left[\mathrm{MCl}_{x}\right]^{0}$ ) is formed at lower chloride concentrations for metals forming strong chloride complexes (e.g., $\mathrm{Zn}(\mathrm{II}))^{36}$ Therefore, these metal complexes have their maximum in distribution ratio at lower $\mathrm{HCl}$ concentrations. The observation of a maximum in the distribution ratio of $\mathrm{Zn}(\mathrm{II})$ as a function of the $\mathrm{LiCl}$ concentration can also be explained using the same concepts. $\mathrm{Zn}$ (II) forms negatively charged chloro complexes at low chloride concentration, where the salting-out effect of $\mathrm{LiCl}$ is less pronounced. Therefore, there are still enough water molecules available to hydrate and stabilize $\mathrm{ZnCl}_{3}^{-}$and $\mathrm{ZnCl}_{4}{ }^{2-}$ slightly more than $\mathrm{ZnCl}_{2}$ in the aqueous phase.

The absolute distribution ratio of a metal also depends on the stability of the chloro complexes in the organic phase. However, the stability of the metal complexes in the organic phase on the distribution ratio is largely unchanged over the whole aqueous chloride concentration range, as the speciation of the metal complex in the organic phase is independent of the chloride concentration in the aqueous phase. ${ }^{21}$ The distribution ratio can, however, be influenced by the accumulation of aqueous phase solutes in the organic phase. This includes $\mathrm{HCl}$ when high aqueous $\mathrm{HCl}$ concentrations are used and extracted metal ions at high loadings. The latter, although significant for industrial metal separations, is outside the scope of the present paper and will be the topic of future work.

3.2. Literature Data on Speciation and Extraction. Linking speciation and extraction allows investigating the way metals are extracted and can be used to test the applicability of the newly proposed extraction model. A speciation profile of the metal chloride complex can be constructed by rewriting eq 6 for each species using the formation constants $(\beta)$ reported in the literature:

$$
x_{\left[\mathrm{MCl}_{x}\right]^{2-x}}=\frac{\beta_{x}\left[\mathrm{Cl}^{-}\right]^{x}}{1+\sum_{i=1}^{m} \beta_{x}\left[\mathrm{Cl}^{-}\right]^{x}}
$$

with $m$ being the maximum amount of chlorides coordinated to $\mathrm{M}^{2+}$ and $\beta_{x}$ being the formation constant for $\left[\mathrm{MCl}_{x}\right]^{2-x}$ species. However, stability constants are given under standard conditions (i.e., zero ionic strength), and significant deviations of the speciation profiles derived from these constants are expected at high ionic strength. To correct for the deviations 
related to the activity coefficient of chloride, an approximation of the activity coefficient model by Helgeson et al. at $25^{\circ} \mathrm{C}$ was used: ${ }^{41,42}$

$$
\log \gamma_{\mathrm{Cl}^{-}}=\frac{-0.509 Z_{\mathrm{Cl}^{-}}^{2} \sqrt{I}}{1+1.22 \sqrt{I}}-\log (1+0.018 I)+0.064 I
$$

where $\gamma_{\mathrm{Cl}^{-}}$denotes the activity coefficient of chloride, $I$ the ionic strength, and $Z_{\mathrm{Cl}^{-}}$the absolute charge of chloride. The complete model can calculate activity coefficients quite accurately, but this approximation is more limited than the complete model of Helgeson et al. The approximation was used, as it is user-friendly and an approximate image of the speciation of a metal in chloride solution is sufficient for these preliminary literature studies. The stability constants of a metal forming strong chloride complexes ( $\mathrm{Zn}$ (II)) and of a metal forming weak chloride complexes (Ni(II)) were used as examples. The resulting speciation profiles were linked to their corresponding extraction profiles using diluted Aliquat 336 and $\mathrm{HCl}$ or $\mathrm{LiCl}$ in the aqueous phase, respectively (Figures 3 and 4). ${ }^{36,43-45}$

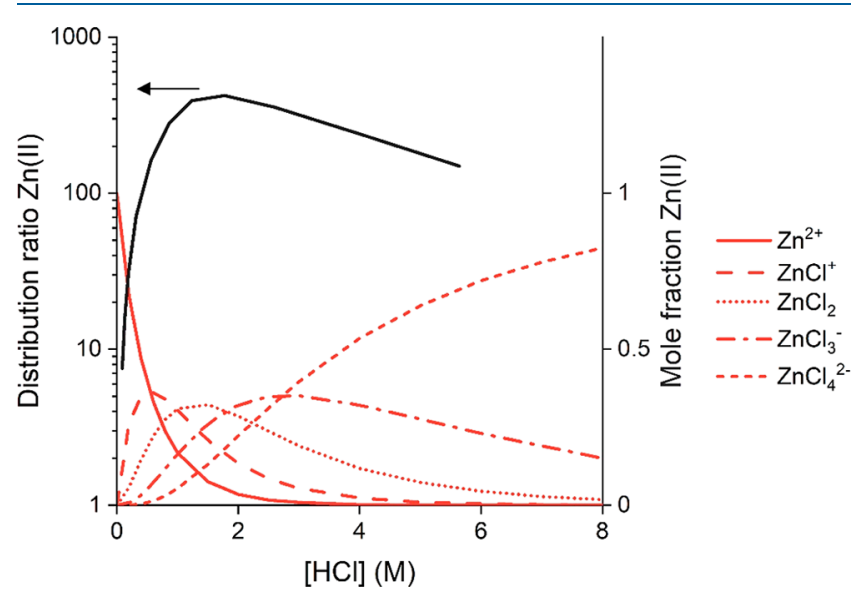

Figure 3. Extraction (black) and speciation profiles (red) of $\mathrm{Zn}$ (II) from $\mathrm{HCl}$ media toward Aliquat 336 in benzene using literature data. $^{44,45}$

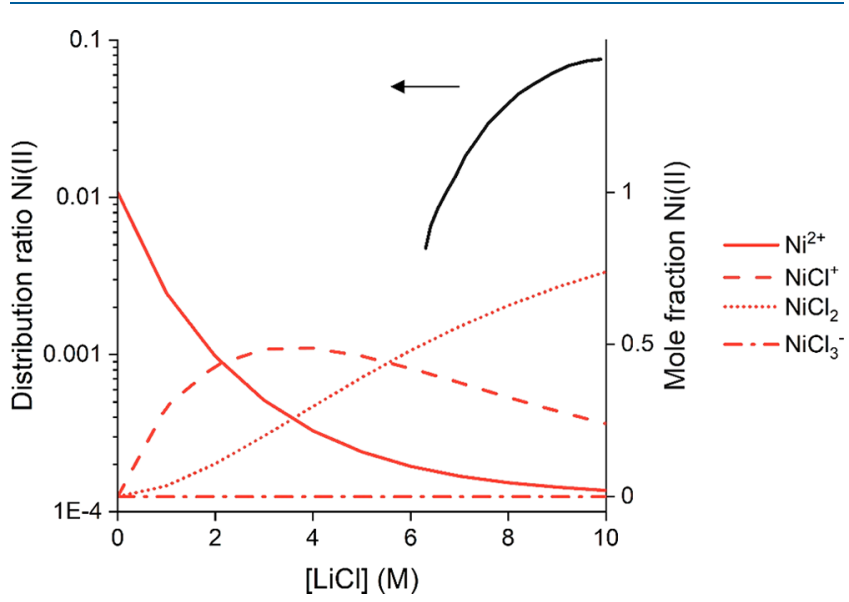

Figure 4. Extraction (black) and speciation profiles (red) of $\mathrm{Ni}(\mathrm{II}$ ) from $\mathrm{LiCl}$ media toward Aliquat 336 in diethylbenzene using literature data. 36,43

The maximum in distribution ratio of $\mathrm{Zn}$ (II) from $\mathrm{HCl}$ media coincides very well with the highest mole fraction of the
$\mathrm{Zn}$ (II) species with the lowest charge density $\left(\mathrm{ZnCl}_{2}\right)$. This species is likely the least hydrated and thus the most extracted according to the model presented above. The extraction is lower at chloride concentrations where the mole fraction of positively or negatively charged $\mathrm{Zn}$ (II) species is higher, but the reduction in distribution ratio is less pronounced when the amount of negatively charged $\mathrm{Zn}$ (II) in the aqueous phase increases. This might be due to the higher $\mathrm{HCl}$ concentration, which acts as a minor salting-out agent by hydrating some water molecules, and due to the smaller increase in charge density of the anionic complexes, which is related to their larger volume.

The extraction of $\mathrm{Zn}(\mathrm{II})$ from $\mathrm{HCl}$ media is significantly higher in comparison to the extraction of $\mathrm{Ni}(\mathrm{II})$ from $\mathrm{HCl}$ media over the whole chloride range, because $\mathrm{Zn}$ (II) forms chloride complexes more easily, which increases the strength of the Lewis acid-base adduct formation in the organic phase (eq 9). Despite the absence of negatively charged $\mathrm{Ni}$ (II) complexes in the aqueous phase, $\mathrm{Ni}$ (II) is still extracted to some extent. This cannot be explained by an anion exchange mechanism, which requires negatively charged species. However, the extraction of $\mathrm{Ni}(\mathrm{II})$ is significant at $\mathrm{LiCl}$ concentrations where the mole fraction of neutral $\mathrm{NiCl}_{2}$ is highest, which is in agreement with our model.

3.3. Metal Speciation. The speciation and extraction curves presented above are only approximate due to the insufficient consideration of the influence of ionic strength. An experimental investigation of the speciation of metal complexes at the same ionic strength as the actual extraction is much more reliable. Therefore, the speciation of $\mathrm{Cu}$ (II) and $\mathrm{Co}$ (II) in $\mathrm{HCl}$ media was investigated and linked to extraction experiments. $\mathrm{Cu}$ (II) and $\mathrm{Co}$ (II) were selected because of the particular bell-shaped form of their distribution ratio as a function of the $\mathrm{HCl}$ concentration and because $\mathrm{Cu}$ (II) and $\mathrm{Co}$ (II) are UV-vis active. Methyltrioctylammonium chloride (TOMAC) (0.2 M) dissolved in toluene was used for the extractions instead of its industrial equivalent (Aliquat 336) to avoid the influence of impurities and to exactly quantify and control the amount of quaternary compounds in the organic phase. Aliquat 336 has only about 90 wt \% quaternary compounds $\left(\mathrm{MeR}_{3} \mathrm{NCl}\right.$ with $\mathrm{R}$ a mixture of $\mathrm{C}_{8}$ and $\mathrm{C}_{10}$ hydrocarbons) while also having about $8 \mathrm{wt} \%$ alcohols and primary secondary and tertiary amines, which react strongly with $\mathrm{HCl}^{31}$

The speciation of $\mathrm{Cu}(\mathrm{II})$ and $\mathrm{Co}$ (II) as a function of the $\mathrm{HCl}$ concentration was studied by UV-vis absorption spectroscopy. UV-vis absorption spectra were recorded for different aqueous solutions containing $\mathrm{Cu}$ (II) $\left(0.5 \mathrm{~g} \mathrm{~L}^{-1}\right)$ or $\mathrm{Co}$ (II) $\left(1.0 \mathrm{~g} \mathrm{~L}^{-1}\right)$ and different amounts of $\mathrm{HCl}(0-11.9 \mathrm{~mol}$ $\left.\mathrm{L}^{-1} \mathrm{Cl}^{-}\right)$. The $\mathrm{Cu}(\mathrm{II})$ solutions for the speciation measurements were made from copper bis(trifluoromethylsulfonyl)imide $\left(\mathrm{Cu}\left(\mathrm{Tf}_{2} \mathrm{~N}\right)_{2}\right)$ to avoid the presence of chlorides from the metal salt at very low $\mathrm{HCl}$ concentrations. No $\mathrm{Tf}_{2} \mathrm{~N}^{-}$was present in the solutions for the extraction experiments. The $\mathrm{Tf}_{2} \mathrm{~N}$ anion does not associate with $\mathrm{Cu}(\mathrm{II})$ in solution, thus resulting in a fully hydrated $\mathrm{Cu}$ (II) complex in water. The color of the $\mathrm{Cu}(\mathrm{II})$ solutions changed gradually from blue toward green-yellow (Figure 5), because of the changes among the five different $\mathrm{Cu}$ (II) species in the aqueous phase: $\mathrm{Cu}^{2+}$, $\mathrm{CuCl}^{+}, \mathrm{CuCl}_{2}, \mathrm{CuCl}_{3}{ }^{-}$, and $\mathrm{CuCl}_{4}{ }^{2-}$. ${ }^{46-48}$

It is known that hydrated octahedral copper ([Cu$\left.\left.\left(\mathrm{H}_{2} \mathrm{O}\right)_{6}\right]^{2+}\right)$ is a weak absorber in the UV-vis spectral region investigated here $(220-500 \mathrm{~nm}$, Figure 6). No absorption is 


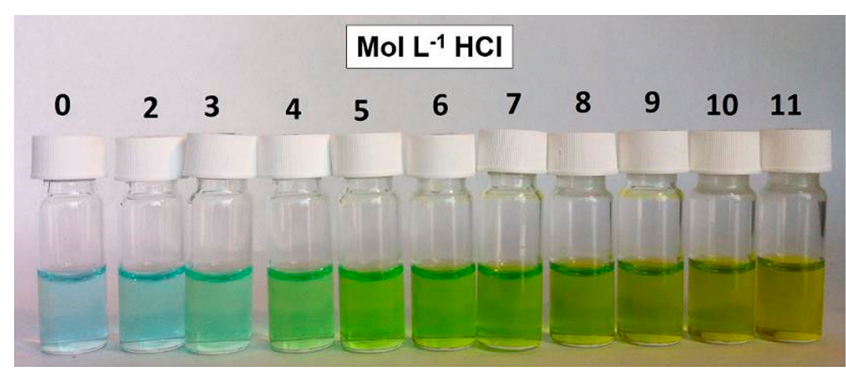

Figure 5. Color change of $0.5 \mathrm{~g} \mathrm{~L}^{-1} \mathrm{Cu}(\mathrm{II})$ (added as the $\mathrm{Cu}\left(\mathrm{Tf}_{2} \mathrm{~N}\right)_{2}$ salt) as a function of the $\mathrm{HCl}$ concentration $\left(0-11 \mathrm{~mol} \mathrm{~L}^{-1} \mathrm{Cl}^{-}\right)$in the aqueous phase.

observed in the measured wavelength range except for a small increase in absorbance below $250 \mathrm{~nm}^{49}$ The presence of $\left[\mathrm{CuCl}\left(\mathrm{H}_{2} \mathrm{O}\right)_{5}\right]^{+}$in solution is evident from the presence of an absorption maximum at $250 \mathrm{~nm} .{ }^{49}$ The individual absorption spectra of the $\left[\mathrm{CuCl}_{2}\left(\mathrm{H}_{2} \mathrm{O}\right)_{4}\right]$ and $\left[\mathrm{CuCl}_{3}\right]^{-}$species, having maxima at 270 and $283 \mathrm{~nm}$, respectively, cannot be directly observed in Figure 6 due to overlap of the absorption spectra of the different species. ${ }^{50,51}$ Note that the geometry changes from the octahedral $\left[\mathrm{CuCl}_{2}\left(\mathrm{H}_{2} \mathrm{O}\right)_{4}\right]$ to the planar triangular $\left[\mathrm{CuCl}_{3}\right]^{-.51}$ The octahedral $\left[\mathrm{Cu}\left(\mathrm{H}_{2} \mathrm{O}\right)_{6}\right]^{2+},\left[\mathrm{CuCl}\left(\mathrm{H}_{2} \mathrm{O}\right)_{5}\right]^{+}$, and $\left[\mathrm{CuCl}_{2}\left(\mathrm{H}_{2} \mathrm{O}\right)_{4}\right]$ complexes do not contribute to the absorption maximum around $380 \mathrm{~nm}$, while the main contribution at $380 \mathrm{~nm}$ comes from the tetrahedral complex $\left[\mathrm{CuCl}_{4}\right]^{2-} .{ }^{52}$ The optical absorption spectra of $\mathrm{Cu}$ (II) in the aqueous phases obtained in this study correspond closely to the absorption spectra of $\mathrm{Cu}(\mathrm{II})$ in $\mathrm{LiCl}$ media presented by Brugger et al. ${ }^{52}$ This shows that the changes in the absorption spectra of $\mathrm{Cu}(\mathrm{II})$ in both studies are related to the change in chloride concentration and not to changes in the $\mathrm{H}^{+}$or $\mathrm{Li}^{+}$ concentrations. Uchikoshi et al. created a similar speciation profile of $\mathrm{Cu}$ (II) in $\mathrm{HCl}$ using MCR-ALS analysis of optical absorption data. ${ }^{51}$ They also analyzed their samples with X-ray absorption spectroscopy to show that the relevant $\mathrm{Cu}(\mathrm{II})$ species are $\left[\mathrm{Cu}\left(\mathrm{H}_{2} \mathrm{O}\right)_{6}\right]^{2+},\left[\mathrm{CuCl}\left(\mathrm{H}_{2} \mathrm{O}\right)_{5}\right]^{+},\left[\mathrm{CuCl}_{2}\left(\mathrm{H}_{2} \mathrm{O}\right)_{4}\right]$, $\left[\mathrm{CuCl}_{3}\right]^{-}$, and $\left[\mathrm{CuCl}_{4}\right]^{2-}$.

It is not possible to derive the exact speciation of $\mathrm{Cu}$ (II) at a given $\mathrm{HCl}$ concentration directly from the $\mathrm{UV}-$ vis absorption spectra. Nevertheless, a full speciation profile and the UV-vis absorption spectra of each of the $\mathrm{Cu}(\mathrm{II})$ species can be deduced using the statistical/mathematical techniques principal component analysis (PCA) and multivariate curve resolutionalternative least squares (MCR-ALS). ${ }^{53,54}$ The mole fractions of the different $\mathrm{Cu}(\mathrm{II})$ species as a function of the $\mathrm{HCl}$ concentrations, as obtained from the PCA-MCR-ALS analysis of the UV-vis absorption spectra, can be found in Figure 7.

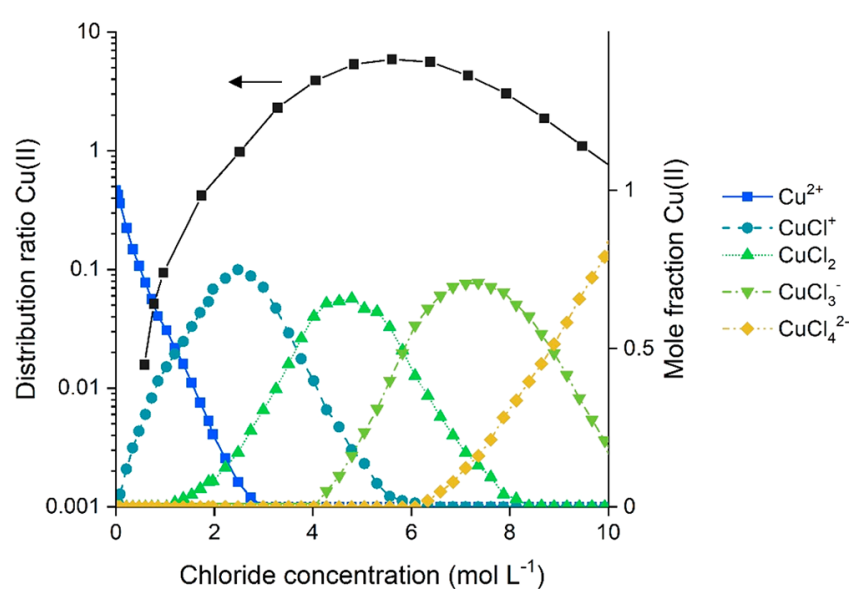

Figure 7. Distribution ratio of $\mathrm{Cu}(\mathrm{II})$ from $\mathrm{HCl}$ media toward 0.2 mol L ${ }^{-1}$ TOMAC in toluene (black) and the mole fractions of the different $\mathrm{Cu}$ (II) species as a function of the chloride concentration in $\mathrm{HCl}$ medium (various colors).

The calculated spectra (see the Supporting Information) and speciation profile are consistent with models, theoretical calculations, X-ray absorption data, and UV-vis absorption analysis reported by other authors. ${ }^{19,49-52}$ Also, the distribution ratio of $\mathrm{Cu}(\mathrm{II})$ for extraction from $\mathrm{HCl}$ media toward 0.2 mol L $\mathrm{L}^{-1}$ TOMAC in toluene is given in Figure 7, to enable a comparison between the speciation and the extraction of $\mathrm{Cu}(\mathrm{II})$.

The lowest distribution ratios for $\mathrm{Cu}(\mathrm{II})$ extracted from $\mathrm{HCl}$ media are found at very low (e.g., $0.5 \mathrm{~mol} \mathrm{~L}^{-1}$ ) and very high $\mathrm{HCl}$ concentrations (e.g., $10 \mathrm{~mol} \mathrm{~L}^{-1}$ ) where the mole fraction of $\left[\mathrm{Cu}\left(\mathrm{H}_{2} \mathrm{O}\right)_{6}\right]^{2+}$ or $\left[\mathrm{CuCl}_{4}\right]^{2-}$ is the highest. In other words, the results depicted in Figure 7 suggest that an increase in $\left[\mathrm{CuCl}_{4}\right]^{2-}$ concentration lowers the distribution ratio, which is

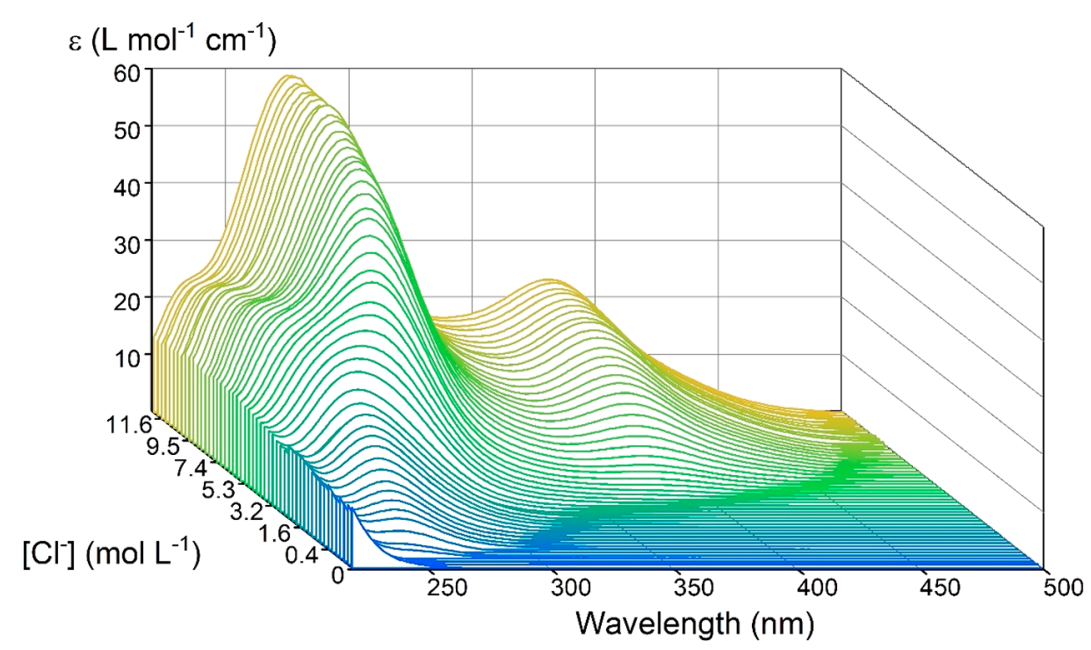

Figure 6. UV-vis absorption spectra of $0.5 \mathrm{~g} \mathrm{~L}^{-1} \mathrm{Cu}(\mathrm{II})$ (added as the $\mathrm{Cu}\left(\mathrm{Tf}_{2} \mathrm{~N}\right)_{2}$ salt) as a function of the $\mathrm{HCl}$ concentration $\left(0-11.8 \mathrm{~mol} \mathrm{~L}^{-1}\right.$ $\left.\mathrm{Cl}^{-}\right)$in the aqueous phase. 


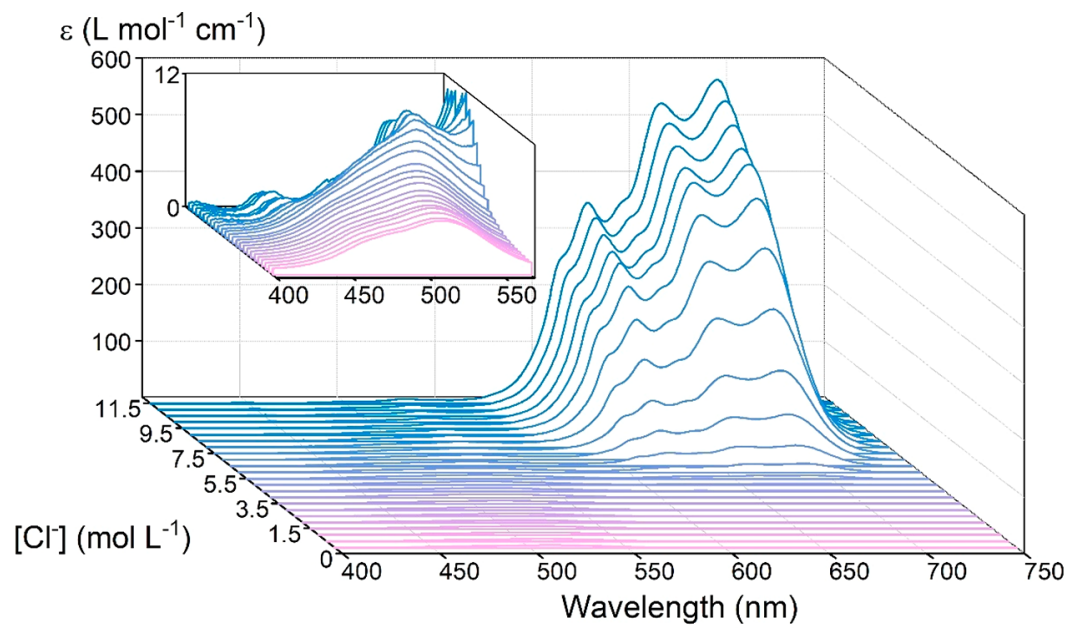

Figure 8. UV-vis absorption spectra of $1.0 \mathrm{~g} \mathrm{~L}^{-1} \mathrm{Co}(\mathrm{II})$ as a function of the $\mathrm{HCl}$ concentration $\left(0.015-11.8 \mathrm{~mol} \mathrm{~L}^{-1} \mathrm{Cl}^{-}\right)$in the aqueous phase.

not in accordance with the generally accepted equations (eqs 1 and 2) for the extraction of metals by basic extractants via anion exchange.

The highest distribution ratio for $\mathrm{Cu}$ (II) is obtained at 5.6 mol L ${ }^{-1} \mathrm{HCl}$, which is close to the maximum in the mole fraction of $\left[\mathrm{CuCl}_{2}\left(\mathrm{H}_{2} \mathrm{O}\right)_{4}\right]$ found at $4.8 \mathrm{~mol} \mathrm{~L}^{-1} \mathrm{HCl}$. Also, the general trend in extraction efficiency seems to follow the general trend in the speciation of $\left[\mathrm{CuCl}_{2}\left(\mathrm{H}_{2} \mathrm{O}\right)_{4}\right]$. The difference between the maximum of the distribution ratio and the maximum of the mole fraction of $\left[\mathrm{CuCl}_{2}\left(\mathrm{H}_{2} \mathrm{O}\right)_{4}\right]$ in the aqueous phase can be explained by the non-negligible solubility of $\mathrm{HCl}$ in the organic phase (vide infra) and changes in the activity of water and the aqueous species due to changes in the $\mathrm{HCl}$ concentration. The $\mathrm{HCl}$ concentration in the aqueous phase was corrected for the loss of $\mathrm{HCl}$ to the organic phase, but no corrections were made for the increase in chloride concentration in the organic phase. The latter was omitted due to the absence of a quantitative relation between the extraction efficiency and the organic $\mathrm{HCl}$ concentration.

Note that the speciation profile is constructed with the same $\mathrm{Cu}$ (II) concentration as used for the extraction studies. Furthermore, the $\mathrm{Cu}(\mathrm{II})$ concentration is significantly lower than the $\mathrm{HCl}$ concentration at the $\mathrm{HCl}$ concentration range of interest for the extraction studies. This concentration profile can be used to explain and predict extractions with a different $\mathrm{Cu}$ (II) concentration, but only when the $\mathrm{Cu}(\mathrm{II})$ concentration is significantly lower than the $\mathrm{HCl}$ concentration. Otherwise, the formation of the different $\mathrm{Cu}$ (II) species would shift to higher $\mathrm{HCl}$ concentration as a significant amount of chlorides are consumed by the formation of the $\mathrm{Cu}$ (II) complexes. This lowers the equilibrium free chloride concentration. In such case, the speciation profile should be adapted using the higher $\mathrm{Cu}(\mathrm{II})$ concentration.

Next, the aforementioned methodology was used to investigate the relation between the extraction behavior of $\mathrm{Co}(\mathrm{II})$ and its aqueous speciation in $\mathrm{HCl}$ media. Although $\mathrm{Cu}$ (II) was added as the $\mathrm{Tf}_{2} \mathrm{~N}$ salt for the spectroscopic study, this lengthy procedure was not repeated for the $\mathrm{Co}$ (II) speciation study, as no significant influence on the speciation curve of $\mathrm{Cu}$ (II) was detected in comparison to what has been reported in the literature. ${ }^{51,52}$ The UV-vis absorption spectra were recorded, and two distinctive regions were visible (Figure 8). Octahedral Co(II) complexes weakly absorb in the region between 400 and $550 \mathrm{~nm}$, while tetrahedral $\mathrm{Co}$ (II) complexes show a much more intense absorption between 550 and 750 nm. ${ }^{55,56}$ The octahedral $\mathrm{Co}$ (II) complexes are mainly present at low $\mathrm{HCl}$ concentrations (up to $7.8 \mathrm{~mol} \mathrm{~L}^{-1}$, vide infra) while tetrahedral $\mathrm{Co}$ (II) complexes are formed at higher $\mathrm{HCl}$ concentrations (from $7.8 \mathrm{~mol} \mathrm{~L}^{-1}$, vide infra). The same can be deduced from the color change of the $\mathrm{Co}$ (II) solutions from pale pink, for $\left[\mathrm{Co}\left(\mathrm{H}_{2} \mathrm{O}\right)_{6}\right]^{2+}$ at low $\mathrm{HCl}$ concentrations, to dark blue, for $\left[\mathrm{CoCl}_{4}\right]^{2-}$ complexes at high $\mathrm{HCl}$ concentrations.

The large difference in the molar absorption coefficients $(\varepsilon)$ of the octahedral and tetrahedral $\mathrm{Co}$ (II) species makes it more difficult to determine the amount of the different Co(II) species present in solution. Presumably, there are five different species present (i.e., $\mathrm{CoCl}_{x}^{2-x}$ with $0 \leq x \leq 4$ ), but many studies on the speciation of $\mathrm{Co}$ (II) in aqueous media are inconsistent. ${ }^{15}$ An extensive study on the speciation of $\mathrm{Co}$ (II) species in $\mathrm{HCl}$ media has been published recently by Uchikoshi, who aimed to remove the ambiguity on the speciation of Co(II). ${ }^{15,57}$ The author used UV-vis and X-ray absorption spectroscopy to arrive at the conclusion that mainly three species exist in aqueous $\mathrm{HCl}$ media, being the octahedral species $\left[\mathrm{Co}\left(\mathrm{H}_{2} \mathrm{O}\right)_{6}\right]^{2+}$ and $\left[\mathrm{CoCl}\left(\mathrm{H}_{2} \mathrm{O}\right)_{5}\right]^{+}$and the tetrahedral species $\left[\mathrm{CoCl}_{4}\right]^{2-}$. This conclusion is consistent with the PCA analysis performed on the UV-vis absorption spectra in the current study, which revealed that three species were necessary to lower the residuals below the experimental error of $1 \%$. Thus, the MCR-ALS analysis of the Co(II) spectra was performed using three species and the resulting spectra of the individual $\mathrm{Co}$ (II) species and the speciation profile of $\mathrm{Co}$ (II) in $\mathrm{HCl}$ can be found in the Supporting Information and Figure 9 , respectively. The speciation profile and individual spectra of $\mathrm{Co}$ (II) are in good agreement with those reported in the literature. $^{15,57}$

The distribution ratios of $\mathrm{Co}$ (II) from aqueous $\mathrm{HCl}$ media toward $0.2 \mathrm{~mol} \mathrm{~L}^{-1}$ TOMAC in toluene are given in Figure 9 to allow for a comparison between its speciation in aqueous media and extraction toward basic extractants. The maximum in distribution ratio of $\mathrm{Co}$ (II) and the highest mole fraction of the $\mathrm{Co}$ (II) species with the lowest charge density $\left(\mathrm{CoCl}^{+}\right)$are both located at $7.6 \mathrm{~mol} \mathrm{~L}^{-1} \mathrm{HCl}$. As for $\mathrm{Cu}(\mathrm{II})$, the similar $\mathrm{HCl}$ concentration for the highest mole fraction of [ $\mathrm{CoCl}-$ $\left.\left(\mathrm{H}_{2} \mathrm{O}\right)_{5}\right]^{+}$and the maximum in distribution ratio of $\mathrm{Co}(\mathrm{II})$ suggest, together with the similar shapes of the distribution curve and speciation curve of $\left[\mathrm{CoCl}\left(\mathrm{H}_{2} \mathrm{O}\right)_{5}\right]^{+}$, that the species 


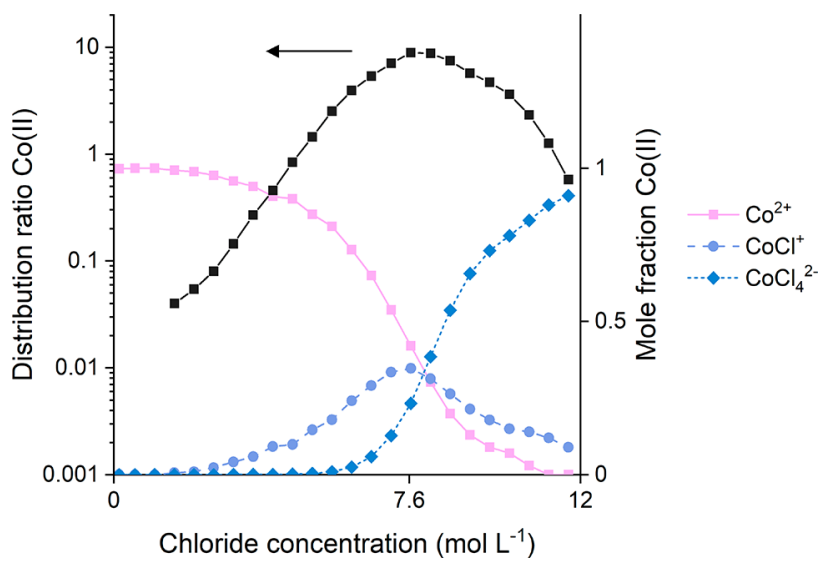

Figure 9. Distribution ratio of $\mathrm{Co}(\mathrm{II})$ from $\mathrm{HCl}$ media toward 0.2 mol L ${ }^{-1}$ TOMAC in toluene (black) and the mole fraction of the different $\mathrm{Co}$ (II) species as a function of the chloride concentration in $\mathrm{HCl}$ medium (various colors).

with the lowest charge density (and lowest hydration) is extracted preferentially.

Two further comments can be made. (1) The species with the lowest charge density is not necessarily the neutral species. $\mathrm{CoCl}^{+}$is the species with the lowest charge density, as $\mathrm{CoCl}_{2}$ is not present in solution. (2) The absence of a changing speciation of the metal complex in the organic phase for both $\mathrm{Cu}$ (II) and $\mathrm{Co}(\mathrm{II})$ (see the Supporting Information for details) shows the validity of linking the extraction as a function of $\mathrm{HCl}$ concentration to the changes in speciation of the aqueous phase.

3.4. Influence of Salting-Out Agents. As mentioned in the introduction of the new extraction model, a cation of a salting-out agent with a higher charge density would be more strongly hydrated and thus would decrease the amount of free water present in solution. Thus, such a salting-out agent would be more efficient in decreasing the effective hydration of the metal complex that is extracted. To qualitatively test the effect of salting-out agents and hydration on metal extraction with basic extractants, extraction experiments were performed with $\mathrm{Zn}$ (II) from aqueous chloride media toward $0.2 \mathrm{~mol} \mathrm{~L}^{-1}$ TOMAC in toluene. Figure 10 shows the distribution ratios of $2.0 \mathrm{~g} \mathrm{~L}^{-1} \mathrm{Zn}$ (II) extracted by $0.2 \mathrm{~mol} \mathrm{~L}^{-1}$ TOMAC in

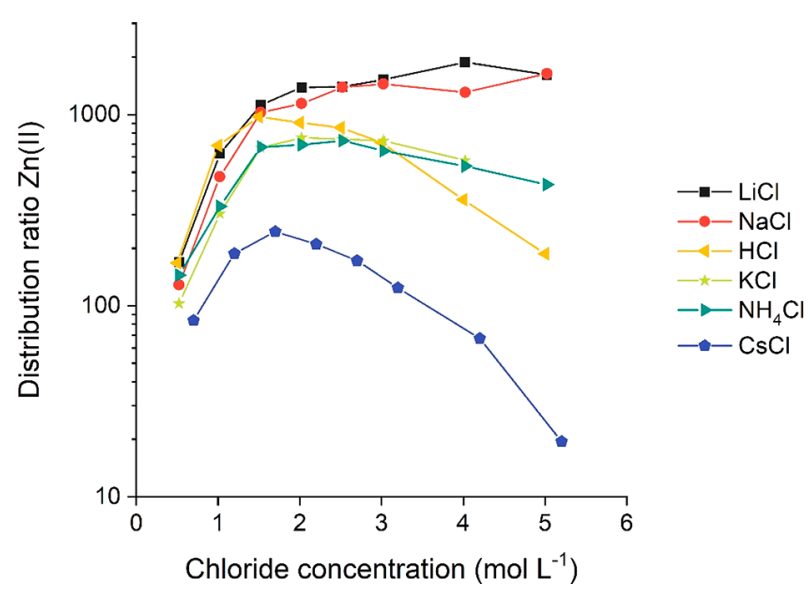

Figure 10. Extraction of $2.0 \mathrm{~g} \mathrm{~L}^{-1} \mathrm{Zn}$ (II) as a function of the initial chloride concentration in the aqueous phase to $0.2 \mathrm{~mol} \mathrm{~L}^{-1}$ TOMAC dissolved in toluene. toluene as a function of the concentration of monovalent salting-out agents in the aqueous phase. $\mathrm{Zn}$ (II) was chosen as it forms strong chloro complexes, ${ }^{44}$ resulting in a maximum in distribution ratio at low chloride concentrations. This way, all alkali chlorides, $\mathrm{NH}_{4} \mathrm{Cl}$, and $\mathrm{HCl}$ could be used as salting-out agents up to a concentration greater than the chloride concentration beyond those where a maximum occurs in the distribution ratio of $\mathrm{Zn}(\mathrm{II})$.

Above $2 \mathrm{~mol} \mathrm{~L}^{-1} \mathrm{Cl}^{-}$, the distribution ratios of $\mathrm{Zn}$ (II) increases in the following order of monovalent salting-out cation:

$$
\mathrm{Li}^{+}>\mathrm{Na}^{+}>\mathrm{H}^{+}>\mathrm{K}^{+} \approx \mathrm{NH}_{4}^{+}>\mathrm{Cs}^{+}
$$

This series is slightly different from the reversed Hofmeister series proposed as the order of hydration for salting-out agents by Dupont and co-workers. ${ }^{17}$ The similar extraction efficiencies for $\mathrm{Zn}(\mathrm{II})$ from $\mathrm{KCl}$ and $\mathrm{NH}_{4} \mathrm{Cl}$ can be explained by their similar ionic radii and consequently their similar charge densities. ${ }^{58,59}$ The positioning of $\mathrm{HCl}$ in the series (eq 12) is not that clear, as its presence in the organic phase also influences the extraction of metals (vide supra). Nevertheless, the similarities between the reversed Hofmeister series and the general decrease in cationic charge density from left to right in eq 12 suggest that the amount of free water molecules in the aqueous phase has a large effect on the shape of the graph displaying the distribution ratio as a function of the chloride concentration.

Another factor influencing the difference in metal extraction from solutions with different salting-out agents would be via a change in metal speciation when the salting-out agent is changed. Different salting-out agents can influence the speciation of a metal because of two reasons: (1) a change in the activity of all species in solution due to different interactions with the cation of a different salting-out agent and (2) a change in free chloride concentration due to the association of mono-, di-, and certainly trivalent salting-out agents. The speciation of $\mathrm{Co}$ (II) in $\mathrm{LiCl}$ was determined via UV-vis absorption spectroscopy and PCA-MCR-ALS, similarly to the determination of $\mathrm{Co}$ (II) species in $\mathrm{HCl}$. The two speciation profiles were compared (Figure 11) to determine the difference in speciation due to a change in monovalent salting-out agent. The associations of both $\mathrm{LiCl}$ and $\mathrm{HCl}$ are

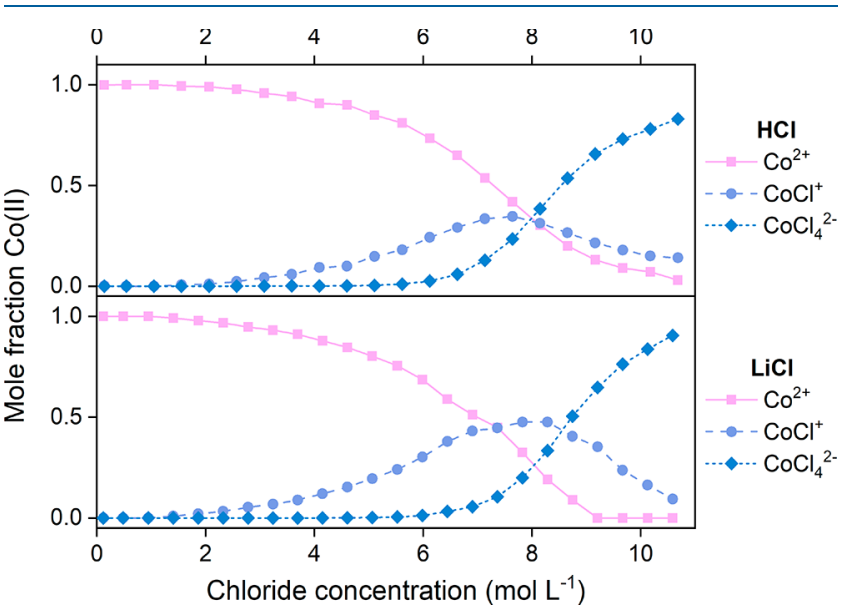

Figure 11. Speciation profile calculated with PCA-MCR-ALS of $\mathrm{Co}$ (II) in $\mathrm{HCl}$ (top) and $\mathrm{LiCl}$ (bottom) as a function of the total chloride concentration. 
similar and considerably lower in comparison to that of divalent and trivalent salting-out agents. This allows observation of the effect of activity on the speciation of $\mathrm{Co}$ (II), although effects of changing the salting-out agent association cannot be completely excluded.

The speciation profile of $\mathrm{Co}(\mathrm{II})$ in $\mathrm{LiCl}$ is very similar to that of $\mathrm{Co}(\mathrm{II})$ in $\mathrm{HCl}$. The curves of $\left[\mathrm{CoCl}\left(\mathrm{H}_{2} \mathrm{O}\right)_{5}\right]^{+}$and $\left[\mathrm{CoCl}_{4}\right]^{2-}$ are shifted to higher chloride concentrations by 0.3 mol L ${ }^{-1}$, but this cannot explain the observed difference in extraction behavior of $\mathrm{Co}$ (II) from $\mathrm{HCl}$ and $\mathrm{LiCl}$ toward basic extractants at high chloride concentrations. To clarify, the distribution curve of $\mathrm{Co}$ (II) from $\mathrm{HCl}$ shows a maximum at 8 mol L $\mathrm{L}^{-1} \mathrm{HCl}$, while the distribution curve of $\mathrm{Co}$ (II) from $\mathrm{LiCl}$ keeps on increasing with increasing chloride concentration. ${ }^{36}$ The mole fraction of $\left[\mathrm{CoCl}_{4}\right]^{2-}$ is still close to 1 at high $\mathrm{LiCl}$ concentrations, which agrees with the observed blue color of the measured solutions. The increase in mole fraction of species with a higher charge density would still decrease the extraction efficiency due to an increased hydration of these $\mathrm{Co}$ (II) species. However, the high $\mathrm{LiCl}$ content decreases the amount of free water molecules drastically, due to association of water molecules with the $\mathrm{Li}(\mathrm{I})$ cation, which has a very high charge density. This results in a net decrease in hydration of $\mathrm{Co}(\mathrm{II})$ in the aqueous phase at high chloride concentrations, so that extraction is more efficient.

Although the similarities among hydration effects, the charge density of the salting-out agent, the Hofmeister series, and the extraction are very clear, the experimental evidence given is only indirect evidence. A direct observation of the hydration sphere or enthalpy of salting-out agents and transition metals as a function of the salting-out concentrations would be very interesting to study the proposed extraction model in more detail and to quantify the model. This will be the subject of further investigation.

3.5. Extraction Behavior of $\mathrm{HCl}$. Apart from the metal extraction itself, the behavior of $\mathrm{HCl}$ in the extraction systems also requires further investigation. A first impression of the $\mathrm{HCl}$ extraction behavior toward basic extractants can be provided by performing extraction experiments on $\mathrm{HCl}$ itself toward water-saturated Aliquat 336 and $0.23 \mathrm{~mol} \mathrm{~L}^{-1}$ Aliquat 336 in toluene (resulting in $0.2 \mathrm{~mol} \mathrm{~L}^{-1}$ quaternary compounds) (Figure 12). Aliquat 336 was chosen here, because these results can be used directly in other works to correct for the $\mathrm{HCl}$ concentration in both phases, as Aliquat 336 is an industrially relevant extractant. However, the metal extractions were performed using TOMAC to increase the accuracy for investigating the extraction mechanism of basic extractants. A smaller scale study was performed using watersaturated TOMAC as extractant for comparison with Aliquat 336, and the $\mathrm{HCl}$ extraction followed the same trend (see the Supporting Information).

The $\mathrm{HCl}$ concentration in both the water-saturated Aliquat 336 and $0.23 \mathrm{~mol} \mathrm{~L}^{-1}$ Aliquat 336 phases increased linearly with the equilibrium $\mathrm{HCl}$ concentration in the aqueous phase, up to a value above the stoichiometric concentration of basic extractant in the organic phase. Volume changes of both phases were negligible $( \pm 0.1 \mathrm{~mL})$, because of a compensating linear decrease in water content in the organic phase. Saturated Aliquat 336 initially contained $20.7 \pm 1.3 \mathrm{wt} \%$ of water, while $13.1 \pm 0.9 \mathrm{wt} \%$ water was left in the Aliquat 336 phase after contact with $11.4 \mathrm{~mol} \mathrm{~L}^{-1} \mathrm{HCl}$. The water content in the 0.23 mol L ${ }^{-1}$ Aliquat 336 in toluene phase was evidently lower, due to the lower polarity of toluene. The Aliquat 336-toluene

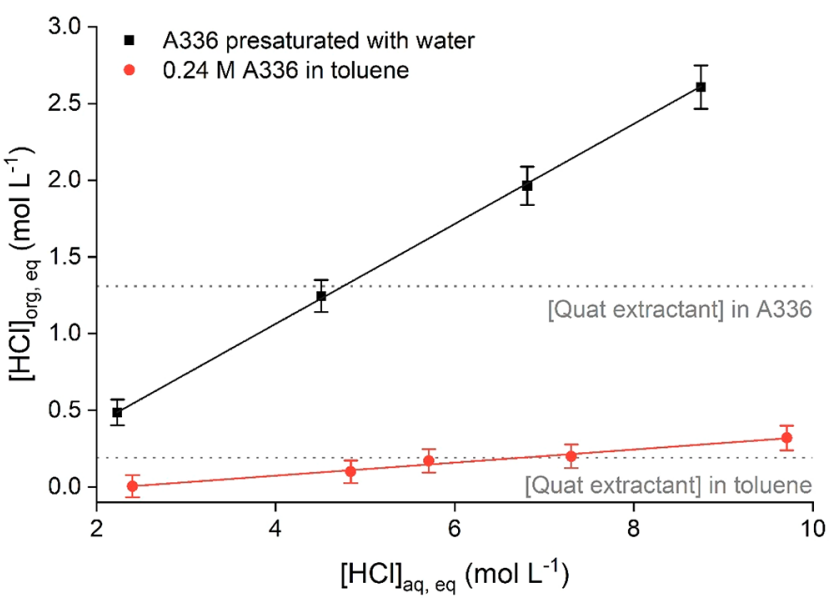

Figure 12. Extraction isotherm of $\mathrm{HCl}$ toward Aliquat 336 presaturated with water $(\boldsymbol{\square})$ and toward $0.23 \mathrm{~mol} \mathrm{~L}^{-1}$ Aliquat 336 in toluene (O). The dotted lines represent the concentration of basic extractant ([Quat extractant]) in water-saturated Aliquat 336 and in $0.23 \mathrm{~mol} \mathrm{~L}^{-1}$ Aliquat 336 in toluene.

phase had a water content of $2.00 \pm 0.25$ wt \% before extraction, which linearly decreased to $0.65 \pm 0.08$ wt \% after contact with $10 \mathrm{~mol} \mathrm{~L}^{-1} \mathrm{HCl}$. On the basis of the proposed extraction mechanism for the extraction of $\mathrm{HCl}$ (eq 13), loading effects should be observed close to the stoichiometric concentration and an organic $\mathrm{HCl}$ concentration higher than the stoichiometric concentration should not be possible. ${ }^{28,29}$

$$
\mathrm{H}^{+}+\mathrm{Cl}^{-}+\overline{\left[\mathrm{NR}_{4}\right][\mathrm{Cl}]} \rightleftharpoons \overline{\left[\mathrm{NR}_{4}\right]\left[\mathrm{HCl}_{2}\right]}
$$

The linear increase in the $\mathrm{HCl}$ concentration in the organic phase as a function of the aqueous equilibrium $\mathrm{HCl}$ concentration, even above a stoichiometric concentration, suggests that the amount of basic extractant does not influence the distribution of $\mathrm{HCl}$ and shows that the extraction mechanism for the formation of $\mathrm{HCl}_{2}^{-}$(eq 13) cannot explain the experimental observations. While it could be argued that the extraction mechanism proposed in eq 13 occurs concurrently with other mechanisms of $\mathrm{HCl}$ extraction, the absence of any loading effects makes this argument unlikely. A change in slope of the distribution ratio as a function of the $\mathrm{HCl}$ concentration should then be observed near the stoichiometric concentration.

If competition between $\mathrm{HCl}$ extraction and metal extraction existed, this would not only be visible in the extraction efficiency of the metal. The $\mathrm{HCl}$ extraction itself should also be influenced by the amount of metal present in the system. Thus, the $\mathrm{HCl}$ concentration in the organic phase at a fixed aqueous equilibrium $\mathrm{HCl}$ concentration should decrease when more metal is present and extracted. The distribution of $\mathrm{HCl}$ between the aqueous phase and water-saturated Aliquat 336 was determined via the density of the aqueous phase before and after extraction (see the Supporting Information for density-concentration conversion). Co(II) was added to the aqueous phase at concentrations between 0.07 and $0.36 \mathrm{~mol}$ $\mathrm{L}^{-1}$, and the amount of extracted $\mathrm{Co}$ (II) was quantified using ICP-OES. No influence of the amount of extracted Co(II) on the extraction of $\mathrm{HCl}$ could be observed (Figure 13), while the extracted amount of $\mathrm{Co}(\mathrm{II})$ significantly decreased the amount of unassociated Aliquat 336 due to the formation of $\left[\mathrm{NR}_{4}\right]_{2}\left[\mathrm{CoCl}_{4}\right]$ complexes in the organic phase. For instance, the extraction of $\mathrm{Co}$ (II) from a $0.36 \mathrm{~mol} \mathrm{~L}^{-1} \mathrm{Co}$ (II) solution at 


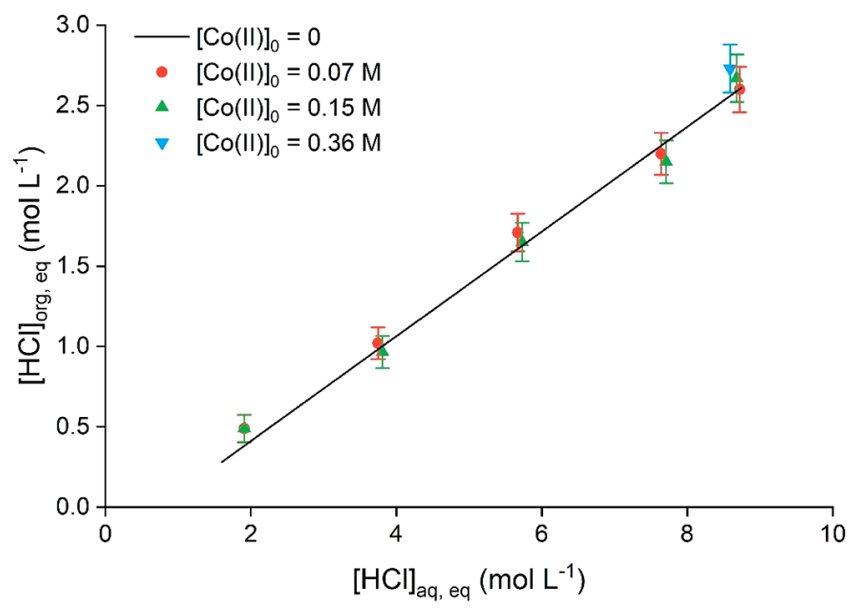

Figure 13. Distribution of $\mathrm{HCl}$ between an aqueous and watersaturated Aliquat 336 phase with varying initial $\mathrm{HCl}$ and $\mathrm{Co}(\mathrm{II})$ concentrations.

$8.7 \mathrm{~mol} \mathrm{~L}^{-1} \mathrm{HCl}$ decreases the available Aliquat 336 concentration by $54 \%$ (complete data in the Supporting Information). Figure 13 shows that the distribution of $\mathrm{HCl}$ is not influenced by the extraction of metal ions; $\mathrm{HCl}$ distributes itself between the aqueous and organic phase in a way that is independent of the amount of $\mathrm{Co}$ (II) extracted.

From Figure 10 it is evident that the decrease in extraction efficiency at high chloride concentrations is not unique for $\mathrm{HCl}$. The curve of the extraction of $\mathrm{Zn}(\mathrm{II})$ from $\mathrm{CsCl}$ is analogous to that of the extraction of $\mathrm{HCl}$, and a slight decrease is seen in the extraction of $\mathrm{Zn}$ (II) from $\mathrm{KCl}$ and $\mathrm{NH}_{4} \mathrm{Cl}$ media above a chloride concentration of $3 \mathrm{~mol} \mathrm{~L}^{-1}$. It should be noted that some precipitation occurred in the aqueous phase before the start of extraction of $\mathrm{Zn}$ (II) from $\mathrm{CsCl}$ due to the formation of the double salt $\mathrm{Cs}_{2} \mathrm{ZnCl}_{4}{ }^{60}$ During extraction the precipitation completely disappeared in all samples as the concentration of $\mathrm{Zn}$ (II) in the aqueous phase decreased. Also, alkali metals are generally not extracted by basic extractants. In fact, the extraction of $\mathrm{Cs}(\mathrm{I})$ in this study is negligible in comparison to the extraction of $\mathrm{Zn}$ (II) and only decreases the available extractant concentration (if it associates with the TOMA cation) by $1 \%$ at the highest $\mathrm{CsCl}$ concentration used in this study (details in the Supporting Information).

The decrease in $\mathrm{Zn}$ (II) extraction from $\mathrm{CsCl}$ cannot be explained by competition between $\mathrm{Zn}$ (II) and $\mathrm{Cs}(\mathrm{I})$ extraction. Thus, the decrease seems to be related to the increased charge density and hydration of negatively charged $\mathrm{Zn}(\mathrm{II})$ species formed at higher $\mathrm{CsCl}$ concentrations. Furthermore, $\mathrm{Cs}^{+}$is a cation with a low charge density, which will not lower the water activity significantly, making it an ineffective salting-out agent. The same explanation can be given for the decrease in extraction efficiency for the extraction of $\mathrm{Zn}(\mathrm{II})$ from high concentrations of $\mathrm{KCl}$ or $\mathrm{NH}_{4} \mathrm{Cl}$. However, the downward trend is much less pronounced, as the charge density of $\mathrm{K}^{+}$and $\mathrm{NH}_{4}{ }^{+}$is higher than that of $\mathrm{Cs}^{+}$, making them more efficient salting-out agents.

\section{CONCLUSIONS}

A novel extraction model for the extraction of metals with basic extractants from chloride media is proposed, because the commonly accepted anion exchange model cannot explain all observed extraction phenomena using basic extractants. The novel model was experimentally tested in several ways: (1) by comparison of speciation and extraction curves of transition metals from the literature and experiments, (2) by studying the effect of different salting-out agents on the metal extraction, and (3) by investigating the distribution of $\mathrm{HCl}$ between the aqueous and organic phase. The proposed extraction model better explains the experimental observations and allows for predicting proper conditions for metal extractions and separations a priori, without the need for changing the extractant concentration. If the distribution ratios are too low for a specific chloride concentration, then it is recommended to select a salting-out cation with a high charge density, such as $\mathrm{Li}^{+}$, to enhance the extraction. In contrast, the use of $\mathrm{HCl}$ is recommended if one wants to extract metal ions that form strong chloride complexes. In this case, very high or very low chloride concentrations result in moderate metal ion distribution ratios, due to the presence of metal species with a higher charge density. This is a qualitative description, and further optimization will be done to gain a deeper insight into the extraction behavior observed at high ionic strength and allow for more quantitative predictions of metal extractions and separations.

\section{ASSOCIATED CONTENT}

\section{S Supporting Information}

The Supporting Information is available free of charge on the ACS Publications website at DOI: 10.1021/acs.inorgchem.9b01782.

Absorption spectra of $\mathrm{Cu}$ (II) and $\mathrm{Co}$ (II) species from PCA-MCR-ALS analysis, UV-vis absorption spectra of $\mathrm{Cu}(\mathrm{II})$ and $\mathrm{Co}(\mathrm{II})$ in the organic phase, $\mathrm{HCl}$ extraction data with TOMAC, corrections on the $\mathrm{HCl}$ concentration from density measurements in a $\mathrm{Co}(\mathrm{II})$ matrix, and data on the $\mathrm{Cs}(\mathrm{I})$ extraction (PDF)

\section{AUTHOR INFORMATION}

\section{Corresponding Author}

*K.B.: e-mail, Koen.Binnemans@kuleuven.be; tel, +32 1632 7446.

ORCID 8

Bieke Onghena: 0000-0002-8809-0842

Koen Binnemans: 0000-0003-4768-3606

\section{Author Contributions}

The manuscript was written through contributions of all authors. All authors have given approval to the final version of the manuscript.

\section{Funding}

The authors thank the KU Leuven (project GOA/13/008) and the FWO Flanders (postdoctoral fellowship to T.V.H. and project G0B6918N) for financial support. The research was supported by the European Research Council (ERC) under the European Union's Horizon 2020 Research and Innovation Programme: Grant Agreement 694078-Solvometallurgy for critical metals (SOLCRIMET). The contents of this publication are the sole responsibility of the authors and do not necessarily reflect the opinion of the European Union.

Notes

The authors declare no competing financial interest. 


\section{ACKNOWLEDGMENTS}

I.B. is grateful to Dr. Ludovic Duponchel for their valuable discussions about the MCR-ALS method. We thank Stijn Raiguel for his fruitful discussion on the proposed extraction model.

\section{REFERENCES}

(1) Rydberg, J.; Cox, M.; Musikas, C.; Choppin, G. R. Solvent Extraction Principles and Practice, Revised and Expanded; CRC Press: New York, 2004.

(2) Xie, F.; Zhang, T. A.; Dreisinger, D.; Doyle, F. A Critical Review on Solvent Extraction of Rare Earths from Aqueous Solutions. Miner. Eng. 2014, 56, 10-28.

(3) Ning, P.; Cao, H.; Lin, X.; Zhang, Y. The Crud Formation during the Long-Term Operation of the $\mathrm{V}(\mathrm{V})$ and $\mathrm{Cr}(\mathrm{VI})$ Extraction. Hydrometallurgy 2013, 137, 133-139.

(4) Lumetta, G. J.; Sinkov, S. I.; Krause, J. A.; Sweet, L. E. Neodymium(III) Complexes of Dialkylphosphoric and Dialkylphosphonic Acids Relevant to Liquid-Liquid Extraction Systems. Inorg. Chem. 2016, 55 (4), 1633-1641.

(5) Rice, N. M. Recent Developments and Potential Uses for Carboxylic Acid Extractants-A Review. Hydrometallurgy 1978, 3 (2), 111-133.

(6) Peppard, D. F.; Mason, G. W.; Maier, J. L. Interrelationships in the Solvent Extraction Behaviour of Scandium, Thorium, and Zirconium in Certain Tributyl Phosphate-Mineral Acid Systems. J. Inorg. Nucl. Chem. 1956, 3 (3), 215-228.

(7) Moore, F. L. Liquid-Liquid Extraction with High-Molecular-Weight Amines; National Academies: 1960.

(8) Vander Hoogerstraete, T.; Wellens, S.; Verachtert, K.; Binnemans, K. Removal of Transition Metals from Rare Earths by Solvent Extraction with an Undiluted Phosphonium Ionic Liquid: Separations Relevant to Rare-Earth Magnet Recycling. Green Chem. 2013, 15 (4), 919-927.

(9) Cattrall, R. W.; Slater, S. J. E. Extraction of Scandium from Aqueous Sulfate Solutions by Bis(3,5,5-Trimethylhexyl)Ammonium Sulfate. Inorg. Chem. 1970, 9 (3), 598-602.

(10) Castillo, J.; Coll, M. T.; Fortuny, A.; Navarro Donoso, P.; Sepúlveda, R.; Sastre, A. M. Cu(II) Extraction Using Quaternary Ammonium and Quaternary Phosphonium Based Ionic Liquid. Hydrometallurgy 2014, 141, 89-96.

(11) Wilson, A. M.; Bailey, P. J.; Tasker, P. A.; Turkington, J. R.; Grant, R. A.; Love, J. B. Solvent Extraction: The Coordination Chemistry behind Extractive Metallurgy. Chem. Soc. Rev. 2014, 43 (1), 123-134.

(12) El-Nadi, Y. A. Solvent Extraction and Its Applications on Ore Processing and Recovery of Metals: Classical Approach. Sep. Purif. Rev. 2017, 46 (3), 195-215.

(13) Sato, T.; Watanabe, H.; Kikuchi, S. Extraction of Some Mineral Acids by High Molecular Weight Quaternary Ammonium Chloride. J. Appl. Chem. Biotechnol. 1975, 25 (1), 63-72.

(14) Yang, Y.; Alexandratos, S. D. Mechanism of Ionic Recognition by Polymer-Supported Reagents: Immobilized Tetramethylmalonamide and the Complexation of Lanthanide Ions. Inorg. Chem. 2010, 49 (3), 1008-1016.

(15) Hofmeister, F. ZurLehrevon der Wirkung der Salze. NaunynSchmiedeberg's Arch. Pharmacol. 1888, 25 (1), 1-30.

(16) Hyde, A. M.; Zultanski, S. L.; Waldman, J. H.; Zhong, Y.-L.; Shevlin, M.; Peng, F. General Principles and Strategies for Salting-Out Informed by the Hofmeister Series. Org. Process Res. Dev. 2017, 21 (9), 1355-1370.

(17) Dupont, D.; Depuydt, D.; Binnemans, K. Overview of the Effect of Salts on Biphasic Ionic Liquid/Water Solvent Extraction Systems: Anion Exchange, Mutual Solubility, and Thermomorphic Properties. J. Phys. Chem. B 2015, 119 (22), 6747-6757.

(18) Landgren, A.; Liljenzin, J.-O. Extraction Behaviour of Technetium and Actinides in the Aliquat-336/Nitric Acid System. Solvent Extr. Ion Exch. 1999, 17 (6), 1387-1401.
(19) Uchikoshi, M. Determination of the Distribution of Cupric Chloro-Complexes in Hydrochloric Acid Solutions at $298 \mathrm{~K}$. J. Solution Chem. 2017, 46 (3), 704-719.

(20) Uchikoshi, M. Determination of the Distribution of CobaltChloro Complexes in Hydrochloric Acid Solutions at $298 \mathrm{~K}$. J. Solution Chem. 2018, 47 (12), 2021-2038.

(21) Onghena, B.; Papagni, E.; Souza, E. R.; Banerjee, D.; Binnemans, K.; Hoogerstraete, T. V. Speciation of Lanthanide Ions in the Organic Phase after Extraction from Nitrate Media by Basic Extractants. RSC Adv. 2018, 8 (56), 32044-32054.

(22) Vander Hoogerstraete, T.; Souza, E. R.; Onghena, B.; Banerjee, D.; Binnemans, K. Mechanism for Solvent Extraction of Lanthanides from Chloride Media by Basic Extractants. J. Solution Chem. 2018, 47 (8), 1351-1372.

(23) Deferm, C.; Onghena, B.; Vander Hoogerstraete, T.; Banerjee, D.; Luyten, J.; Oosterhof, H.; Fransaer, J.; Binnemans, K. Speciation of Indium(III) Chloro Complexes in the Solvent Extraction Process from Chloride Aqueous Solutions to Ionic Liquids. Dalton Trans 2017, 46, 4412-4421.

(24) Cui, L.; Cheng, F.; Zhou, J. Behaviors and Mechanism of Iron Extraction from Chloride Solutions Using Undiluted Cyphos IL 101. Ind. Eng. Chem. Res. 2015, 54 (30), 7534-7542.

(25) du Preez, J. G.H. Recent Advances in Amines as Separating Agents for Metal Ions. Solvent Extr. Ion Exch. 2000, 18 (4), 679-701.

(26) Komasawa, I.; Maekawa, Y.; Otake, T. Extraction of Cobalt from Hydrochloric Acid by Tri-n-Octylmethylammonium Chloride Dissolved in Benzene. J. Chem. Eng. Jpn. 1987, 20 (1), 41-46.

(27) Sato, T. The Extraction of Cobalt (II) from Hydrochloric Acid Solution by Tri-n-Octylamine. J. Inorg. Nucl. Chem. 1967, 29 (2), $547-553$

(28) Good, M. L.; Bryan, S. E.; Holland, F. F.; Maus, G. J. Nature of the Hydrogen Ion Effect on the Extraction of $\mathrm{Co}(\mathrm{II})$ from Aqueous Chloride Media by Substituted Ammonium Chlorides of High Molecular Weight. J. Inorg. Nucl. Chem. 1963, 25 (9), 1167-1173.

(29) Komasawa, I.; Kurokawa, N.; Maekawa, Y.; Otake, T. Extraction of Hydrochloric Acid by Tri-n-Octylammonium Chloride in Various Diluents. J. Chem. Eng. Jpn. 1986, 19 (6), 592-598.

(30) Mettler-Toledo, Density applications: https://www.mt.com/ us/en/home/applications/Application_Browse_Laboratory Analytics/Density.tabs.applications.html (accessed Oct 19, 2017).

(31) Lee, G. L.; Cattrall, R. W.; Daud, H.; Smith, J. F.; Hamilton, I. C. The Analysis of Aliquat-336 by Gas Chromatography. Anal. Chim. Acta 1981, 123, 213-220.

(32) Jaumot, J.; de Juan, A.; Tauler, R. MCR-ALS GUI 2.0: New Features and Applications. Chemom. Intell. Lab. Syst. 2015, 140, 1-12.

(33) de Juan, A.; Tauler, R. Multivariate Curve Resolution (MCR) from 2000: Progress in Concepts and Applications. Crit. Rev. Anal. Chem. 2006, 36 (3-4), 163-176.

(34) Andersson, S.; Eberhardt, K.; Ekberg, C.; Liljenzin, J.-O.; Nilsson, M.; Skarnemark, G. Determination of Stability Constants of Lanthanide Nitrate Complex Formation Using a Solvent Extraction Technique. Radiochim. Acta 2006, 94 (8), 469-474.

(35) Larsson, K.; Binnemans, K. Separation of Rare Earths by SplitAnion Extraction. Hydrometallurgy 2015, 156, 206-214.

(36) Seeley, F. G.; Crouse, D. J. Extraction of Metals from Chloride Solutions and Amines. J. Chem. Eng. Data 1966, 11 (3), 424-429.

(37) Horne, R. A. The Adsorption of Zinc(II) on Anion-Exchange Resins. I. The Secondary Cation Effect. J. Phys. Chem. 1957, 61 (12), $1651-1655$.

(38) Loyson, P. The Solvent Extraction of Zinc from Lithium Chloride by Aliquat 336 Chloride, Bromide and Iodide in Chloroform: An Analytical Investigation. Solvent Extr. Ion Exch. 2000, 18 (1), 25-39.

(39) Housecroft, C. E.; Jenkins, H. D. B. Absolute Ion Hydration Enthalpies and the Role of Volume within Hydration Thermodynamics. RSC Adv. 2017, 7 (45), 27881-27894.

(40) Qi, D. Extractants Used in Solvent Extraction-Separation of Rare Earths: Extraction Mechanism, Properties, and Features. In 
Hydrometallurgy of Rare Earths; Qi, D., Ed.; Elsevier: 2018; Chapter 2, pp 187-389. DOI: 10.1016/B978-0-12-813920-2.00002-7.

(41) Helgeson, H.; Kirkham, D.; Flowers, G. Theoretical Prediction of the Thermodynamic Behavior of Aqueous Electrolytes by High Pressures and Temperatures; IV, Calculation of Activity Coefficients, Osmotic Coefficients, and Apparent Molal and Standard and Relative Partial Molal Properties to 600 Degrees C and 5kb. Am. J. Sci. 1981, 281, 1249-1516.

(42) Oelkers, E. H.; Helgeson, H. C. Triple-Ion Anions and Polynuclear Complexing in Supercritical Electrolyte Solutions. Geochim. Cosmochim. Acta 1990, 54 (3), 727-738.

(43) Bissonett, K. Raman Investigation of Nickel Chloride Complexation Under Hydrothermal Conditions; University of Guelph: Ontario, Canada, 2013.

(44) Aparicio, J. L.; Elizalde, M. P. Activity Coefficient Calculations Applied to $\mathrm{ZnCl}_{2}$ in $\mathrm{LiCl}$ Media. Distinction between the Real Activity Coefficient and the Effect of Complexation. J. Solution Chem. 1996, 25 (11), 1055-1069.

(45) Sato, T.; Nakamura, T.; Fujimatsu, T. Extraction of Bivalent Manganese, Cobalt, Copper, Zinc, and Cadmium from Hydrochloric Acid Solutions by Long-Chain Alkyl Quaternary Ammonium Chloride in Various Organic Solvents. Bull. Chem. Soc. Jpn. 1981, 54 (9), 2656-2661.

(46) Wang, M.; Zhang, Y.; Muhammed, M. Critical Evaluation of Thermodynamics of Complex Formation of Metal Ions in Aqueous Solutions III. The System $\mathrm{Cu}(\mathrm{I}, \mathrm{II})-\mathrm{Cl}^{-}-\mathrm{e}$ at $298.15 \mathrm{~K}$. Hydrometallurgy 1997, 45 (1), 53-72.

(47) Zhang, N.; Zhou, Q.; Yin, X.; Zeng, D. Trace Amounts of Aqueous Copper(II) Chloride Complexes in Hypersaline Solutions: Spectrophotometric and Thermodynamic Studies. J. Solution Chem. 2014, 43 (2), 326-339.

(48) Bjerrum, J.; Skibsted, L. H. Weak Chloro Complex Formation by Copper(II) in Aqueous Chloride Solutions. Inorg. Chem. 1986, 25 (14), 2479-2481.

(49) Xia, F.-F.; Yi, H.-B.; Zeng, D. Hydrates of $\mathrm{Cu}^{2+}$ and $\mathrm{CuCl}^{+}$in Dilute Aqueous Solution: A Density Functional Theory and Polarized Continuum Model Investigation. J. Phys. Chem. A 2010, 114 (32), 8406-8416.

(50) Xia, F.-F.; Yi, H.-B.; Zeng, D. Hydrates of Copper Dichloride in Aqueous Solution: A Density Functional Theory and Polarized Continuum Model Investigation. J. Phys. Chem. A 2009, 113 (51), 14029-14038.

(51) Uchikoshi, M.; Shinoda, K. Determination of Structures of Cupric-Chloro Complexes in Hydrochloric Acid Solutions by UV-Vis and X-Ray Absorption Spectroscopy. Struct. Chem. 2019, 30 (1), 6174.

(52) Brugger, J.; McPhail, D. C.; Black, J.; Spiccia, L. Complexation of Metal Ions in Brines: Application of Electronic Spectroscopy in the Study of the $\mathrm{Cu}(\mathrm{II})-\mathrm{LiCl}-\mathrm{H}_{2} \mathrm{O}$ System between 25 and $90^{\circ} \mathrm{C}$. Geochim. Cosmochim. Acta 2001, 65 (16), 2691-2708.

(53) Jaumot, J.; Escaja, N.; Gargallo, R.; González, C.; Pedroso, E.; Tauler, R. Multivariate Curve Resolution: A Powerful Tool for the Analysis of Conformational Transitions in Nucleic Acids. Nucleic Acids Res. 2002, 30 (17), No. 92e.

(54) Esteban, M.; Ariao, C.; DaDaz-Cruz, J. M.; DaDaz-Cruz, M. S.; Tauler, R. Multivariate Curve Resolution with Alternating Least Squares Optimisation: A Soft-Modelling Approach to Metal Complexation Studies by Voltammetric Techniques. TrAC, Trends Anal. Chem. 2000, 19 (1), 49-61.

(55) Cotton, F. A.; Goodgame, D. M. L.; Goodgame, M. The Electronic Structures of Tetrahedral Cobalt(II) Complexes. J. Am. Chem. Soc. 1961, 83 (23), 4690-4699.

(56) Pan, P.; Susak, N. J. Co(II)-Chloride and -Bromide Complexes in Aqueous Solutions up to $5 \mathrm{~m} \mathrm{NaX}$ and $90^{\circ} \mathrm{C}$ : Spectrophotometric Study and Geological Implications. Geochim. Cosmochim. Acta 1989, 53 (2), 327-341.

(57) Uchikoshi, M.; Shinoda, K. Determination of Structures of Cobalt(II)-Chloro Complexes in Hydrochloric Acid Solutions by XRay Absorption Spectroscopy at 298 K. Struct. Chem. 2019, 30, 945.
(58) Sidey, V. On the Effective Ionic Radii for Ammonium. Acta Crystallogr., Sect. B: Struct. Sci., Cryst. Eng. Mater. 2016, 72 (4), 626633.

(59) Shannon, R. D. Revised Effective Ionic Radii and Systematic Studies of Interatomic Distances in Halides and Chalcogenides. Acta Crystallogr., Sect. A: Cryst. Phys., Diffr., Theor. Gen. Crystallogr. 1976, 32 (5), 751-767.

(60) McGinnety, J. A. Crystal Structure, Crystal Forces, and Charge Distribution in Salts of the Tetrachlorozincate Anion. Inorg. Chem. 1974, 13 (5), 1057-1061. 